\title{
QUALIDADE DO LIXIVIADO E SUA INTERFERÊNCIA NA ÁGUA SUBTERRÂNEA ADJACENTE AO ATERRO SANITÁRIO DE PALMEIRA DAS MISSÕES (RS)
}

Lucimara Bragagnolo

Suéllen Tonatto Ferrazzo

Fernanda Machado Brum

Eduardo Pavan Korf

Altemir José Mossi

\section{RESUMO}

A disposição final de Resíduos Sólidos Urbanos (RSU) em aterros corresponde a técnica de tratamento de resíduos mais difundida no mundo, porém, estes locais apresentam fontes potenciais de poluição, necessitando constante monitoramento ambiental. Assim, este estudo avaliou a relação entre qualidade do lixiviado gerado no aterro sanitário de Palmeira das Missōes e da água subterrânea local. Para tanto, realizou-se uma avaliação histórica da qualidade da água subterrânea e de informaçôes do efluente bruto e tratado. Os dados dos parâmetros da qualidade da água subterrânea foram submetidos à estatística descritiva e ao Teste t de Student. A avaliação da qualidade do lixiviado tratado revelou que, dos 40 parâmetros avaliados, 9 apresentaram concentraçóes acima do valor máximo permitido (VMP) estabelecidos nas resoluçóes brasileiras. Para a água subterrânea, dentre os 30 parâmetros avaliados, 10 estão presentes em concentrações superiores ao VMP. O teste estatístico revelou que a alcalinidade total, $\mathrm{Pb}, \mathrm{OD}$, DBO5 SDT e ST apresentaram um aumento significativo em pelo menos uma das análises dos poços à jusante em relaçáo ao poço à montante, porém, somente $\mathrm{o} \mathrm{Pb}$ e a $\mathrm{DBO} 5$ estão presentes em concentração superior ao VMP. Tais resultados demonstraram que o lixiviado gerado no aterro está afetando a qualidade da água subterrânea local e, também, espera-se que contribuam para a melhor gestão dos RSU e dos recursos hídricos subterrâneos.

Palavras-chave: resíduos sólidos; aterro de resíduos; estudo hidrogeológico, parâmetros físico-químicos.

\section{ABSTRACT}

The Municipal Solid Waste (MSW) final disposal in landfills corresponds to waste treatment technique that has been practiced the most in the world, however, these sites present potential sources of pollution, requiring constant environmental monitoring. Thus, this study evaluated the relationship between the leachate quality generated at the landfill from Palmeira das Missôes (RS) and the local groundwater. For this, it has been carried a historical evaluation of data from the groundwater quality and treated effluent. The data on the groundwater quality parameters has been submitted to descriptive statistics and to Student's $\mathrm{t}$-test. The evaluation of the treated leachate quality revealed that, for the 40 evaluated parameters, 9 had concentrations above the allowed maximum value (AMV) established in the Brazilian resolutions. For groundwater, among the 30 parameters evaluated, 10 are present in concentrations higher than AMV. Statistical analysis revealed that total alkalinity, $\mathrm{Pb}, \mathrm{OD}, \mathrm{BOD} 5, \mathrm{TDS}$ and TS showed a significant increase in at least one of the analyzes from downstream wells, compared to the upstream well, but only $\mathrm{Pb}$, and BOD5 are present in higher concentration than AMV. These results demonstrated that the leachate generated in the landfill is affecting the local groundwater quality. In addition, it's expected that these results contribute to the improvement of management of the MSW and groundwater resources.

Keywords: solid waste; landfill; hydrogeology study; physical-chemical parameters. 


\section{INTRODUÇÃO}

Em âmbito global, o descarte em aterros consiste na forma de destinação final dos resíduos mais frequente em países em desenvolvimento, sendo ainda praticada em países desenvolvidos como Estados Unidos, Canadá e Austrália (JOVANOV; VUJIĆ; VUJIĆ, 2018; NAVEEN et al., 2017; SCOTT et al., 2005; TANG et al., 2018; ZHAN et al., 2014). Conforme informaçōes do Diagnóstico do Manejo de Resíduos Sólidos Urbanos de 2016, no país, 59,0\% dos RSU coletados são encaminhados à aterros sanitários, 9,6\% à aterros controlados, $10,3 \%$ à lixốes, $3,1 \%$ à unidades de triagem, $0,2 \%$ à unidades de compostagem, e sobre a parcela de $17,7 \%$ não há informações da destinação final (BRASIL, 2018).

A disposição final dos RSU em aterros é considerada a técnica mais difundida devido ao menor custo de investimento e operaçáo e pelos requisitos técnicos, em relação à outras formas de tratamento (HU; DU; LONG, 2017; LIMA et al., 2018). Dentre os possíveis impactos ambientais decorrentes $\mathrm{da}$ referida atividade, a contaminaçáo da água subterrânea pelo lixiviado é considerado o com maior potencial negativo (MAO et al., 2018; SCOTT et al., 2005; TANG et al., 2018). A quantidade total de contaminantes emitidos em aterros depende, dentre outros fatores, do tipo de resíduo depositado, das mudanças físico-químicas que ocorrem, e também, da proteção da superfície do solo. $\mathrm{O}$ transporte de contaminantes do aterro oriundo do lixiviado ocorre, principalmente, através da água da chuva com escoamento subterrâneo e superficial, caso não houver medidas de controle adequadas (ADAMCOVÁ et al., 2017).

O lixiviado de um aterro sanitário é compreendido como um fator complexo na qual existem a mistura de diversos produtos químicos, incluindo matéria orgânica, sais inorgânicos, poluentes orgânicos e metais pesados, cada um em concentraçóes que variam de acordo com as características físicas, químicas e processos que ocorrem dentro do aterro sanitário (KJELDSEN et al., 2002). A poluiçáo do meio ambiente oriunda do contato com o lixiviado, deve-se a um conjunto de fatores que podem abranger a liberação de ácidos voláteis, amônia, substâncias orgânicas cloradas e não-cloradas e metais pesados, representando fontes de compostos tóxicos aos organismos vivos (BACCINI et al., 1987; CHRISTENSEN et al., 2001; KULIKOWSKA; KLIMIUK, 2008; REGADÍO et al., 2012).

Segundo Lee e Jones-Lee (1996), a decomposição dos resíduos em aterros sanitários corresponde à uma ameaça constante ao meio ambiente e à um processo que ocorre de forma mais intensa após o período de 30 a 50 anos. Uma vez que a disposição de resíduos em aterros representa um risco potencial à saúde humana e ao meio ambiente, mesmo que o projeto, a implantação e a operação estejam adequados, o seu monitoramento deve ser permanente durante toda a vida útil e após o seu encerramento, visando prevenir eventuais impactos ambientais (CHRISTENSEN et al., 2001; JOVANOV; VUJIĆ; VUJIĆ, 2018; MAITI et al., 2016). Além disso, para tornar confiável o planejamento e a gestão do aterro, a realização de um bom diagnóstico, monitoramento e avaliaçôes precisas podem evitar potenciais impactos, tais como: incêndios e explosóes; instabilidade geotécnica das massas de resíduos; danos à vegetação; odores desagradáveis; poluição das águas subterrâneas; poluição do ar e aquecimento global (CALVO et al., 2005; MANZO et al., 2017; PIVATO; DI SANTE; MORETTO, 2017).

Neste contexto, a avaliação da qualidade do tratamento do lixiviado do aterro e o seu manejo representam uma séria questão a ser tratada em todo mundo, e que está começando a receber maior atenção, principalmente em países em desenvolvimento. Simultaneamente, deve ser realizado o monitoramento da qualidade dos recursos hídricos nas proximidades do aterro, como da água subterrânea, devido aos riscos que a sua contaminação por lixiviado pode exercer sobre a saúde humana, a vida aquática e cadeias alimentares (NAVEEN et al., 2017). Considerando que os aterros são as principais fontes de riscos às águas subterrâneas, que o lixiviado gerado é um efluente altamente concentrado e complexo de ser tratado, e que a contaminação desse recurso hídrico consiste em um risco substancial aos seus usuários, o impacto do lixiviado na qualidade das águas subterrâneas tem dado origem a muitos estudos, no decorrer dos últimos anos. Cabe ressaltar que, tais estudos também são importantes para a identificação de possíveis ameaças aos moradores que 
utilizam os recursos hídricos nas proximidades dos aterros (HOSSAIN; DAS; HOSSAIN, 2014), bem como para auxiliar na tomada de decisóes quanto à gestão do recurso hídrico subterrâneo e para adoção de técnicas de remediação e contenção de plumas de contaminação, caso forem detectadas (BECK et al., 2010; HAN et al., 2016).

Diante deste cenário, o objetivo inerente a este estudo consistiu na avaliação da qualidade do lixiviado bruto e tratado e da água subterrânea no aterro sanitário localizado no município de Palmeira das Missões/RS, bem como da relação entre estes dois fatores. Este aterro, apesar de estar licenciado pelo órgáo de Licenciamento Estadual do Rio Grande do Sul - FEPAM, de acordo com todas as normas e legislaçóes necessárias, carece de um estudo aprofundado e monitoramento permanente com relação às possíveis contaminaçóes de mananciais hídricos pelo lixiviado gerado neste local.

\section{METODOLOGIA}

\section{CARACTERIZAÇÃO DA ÁREA DE ESTUDO}

O objeto de estudo refere-se ao aterro sanitário de uma empresa privada, localizado no município de Palmeira das Missóes, pertencente a Microrregiáo de Carazinho e a Mesorregião Noroeste Rio-Grandense., $\mathrm{O}$ aterro recebe apenas resíduos sólidos urbanos, não perigosos (BRASIL, 2011a), ou de Classe II, conforme a Norma 10004 (ASSOCIAÇĀO BRASILEIRA DE NORMAS TÉCNICAS, 2004), de 27 municípios. A localização do município que abrange a área do aterro e a dos municípios atendidos por ele estáo apresentadas na Figura 1.

O empreendimento possui uma área total de 12 ha, com pavilhóes de triagem $(675 \mathrm{~m} 2)$, célula 1 encerrada $(7.973,14 \mathrm{~m} 2)$ e duas células em operação: célula $2(3.150,00 \mathrm{~m} 2)$ e célula $3(4.664,24 \mathrm{~m} 2)$, esta

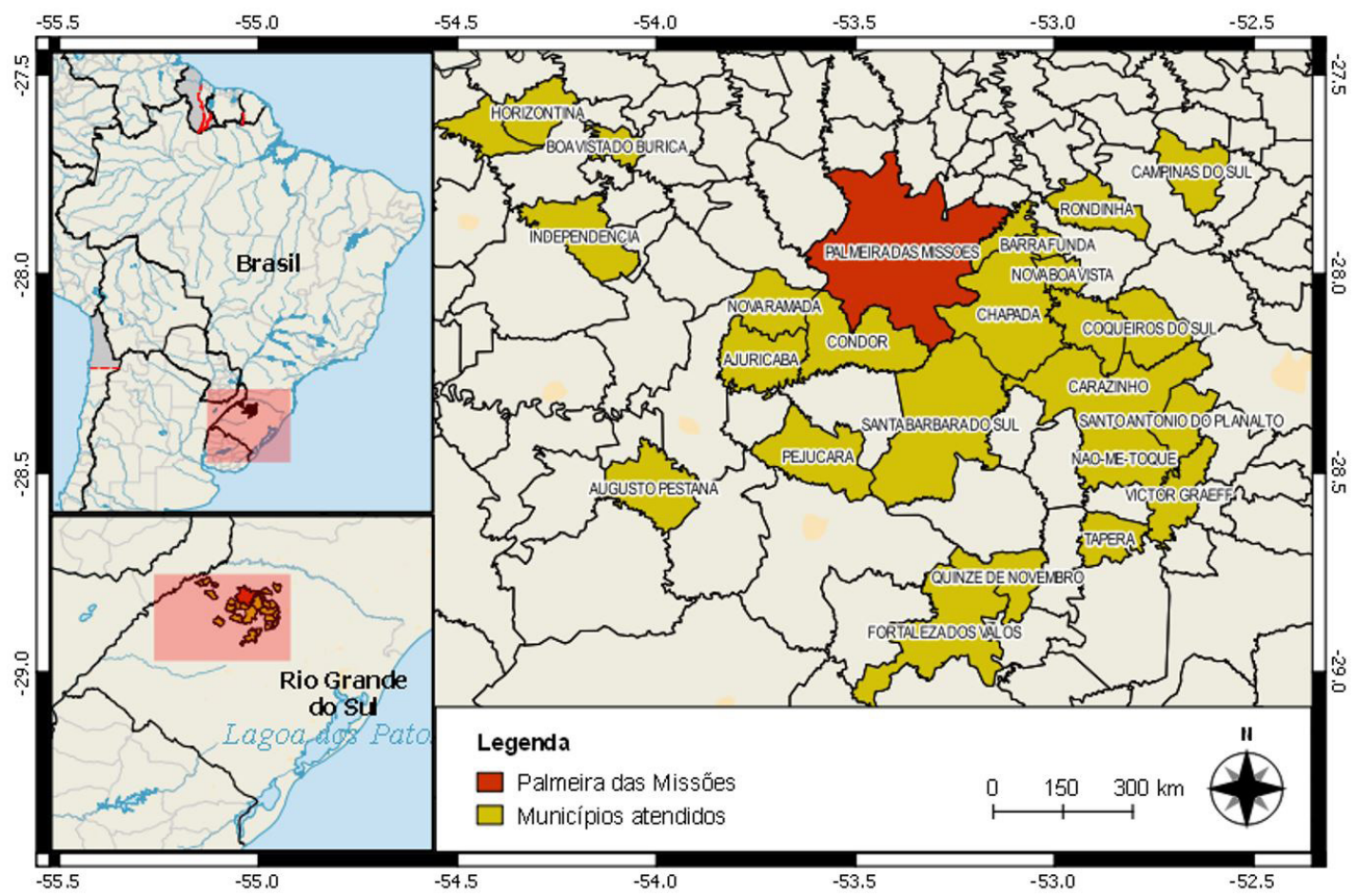

Figura 1. Mapa de localização de Palmeira das Missóes e dos municípios atendidos pelo aterro sanitário. Fonte: Elaborado pelos autores. 
última com vida útil aproximada de 03 (três) anos. $\mathrm{O}$ aterro ainda dispóe de um sistema de drenagem e de queima de gases, através de flares, de uma Estação de Tratamento de Efluentes (ETE) por sistema físico-químico, lagoa aerada e banhado construído e possui 6 poços de monitoramento de águas subterrâneas, sendo 1 a montante e 5 a jusante (Figura 2).

Com relação a hidrogeologia, conforme informaçôes repassadas pelos responsáveis técnicos do aterro sanitário, a unidade predominante na área de estudo é um aquífero fissural, pertencente ao Sistema Aquífero Serra Geral I (SASG I). Além disso, o lençol freático não foi detectado até 15 metros de profundidade em nenhuma perfuração nas áreas onde ocorre a disposição de resíduos, tendo esse sido observado somente a jusante da área, onde atualmente estão instalados os poços de monitoramento.

\section{CARACTERIZAÇÃO DO EFLUENTE LIXIVIADO E DA ÁGUA SUBTERRÂNEA}

\section{Caracterizaçáo do lixiviado gerado nas células do aterro}

As células de recebimento do aterro sanitário geram lixiviado que é tratado no próprio aterro na ETE, cujas etapas de tratamento estão esquematizadas na Figura 3. A estação é basicamente composta por sistemas primário e secundário de tratamento. O sistema primário é composto por etapas de coagulação, decantação e filtração. Já o sistema secundário engloba uma lagoa aerada e, como polimento, um banhado construído. Ainda, o lodo que é gerado durante o processo de tratamento é encaminhado para as próprias células de disposição. Coletas de amostras do efluente são realizadas anterior à etapa de coagulação e ao final do tratamento, no banhado construído.

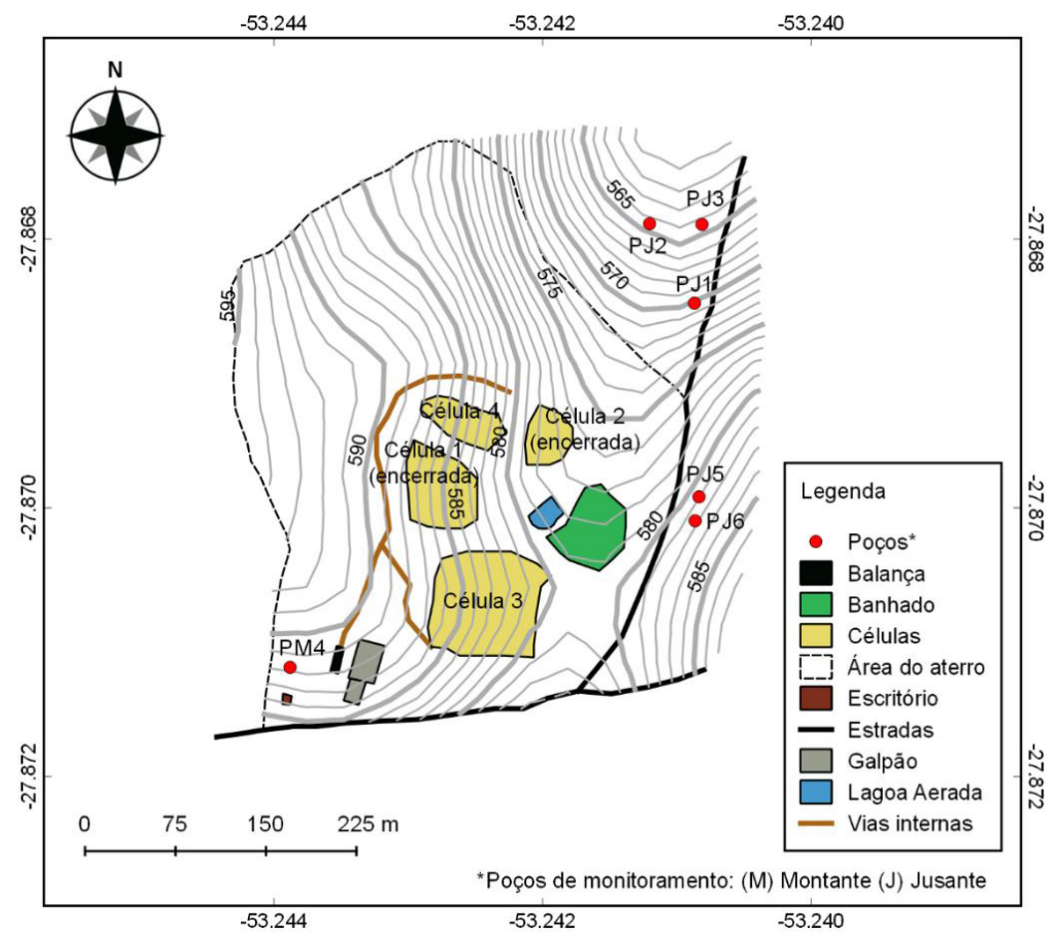

Figura 2. Planta do aterro sanitário de Palmeira das Missóes e localização dos poços de monitoramento. Fonte: Elaborado pelos autores. 


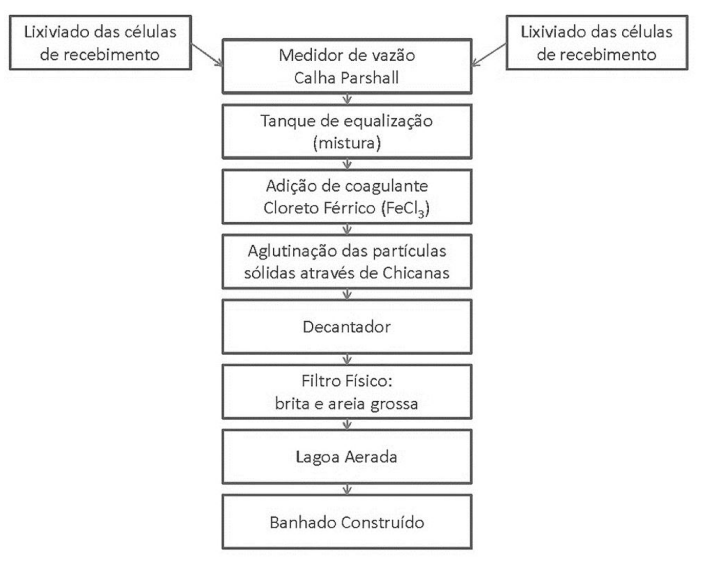

Figura 3. Fluxograma da Estação de tratamento de efluentes.

Com a finalidade de identificar possíveis tendências no teor de contaminantes, os efluentes gerados na disposição dos resíduos nas células do aterro sanitário, nas suas condiçóes bruta e tradada, foram analisados estatisticamente por meio do levantamento e tabulação das informaçóes de análises realizadas por laboratórios cadastrados pelo órgão ambiental ao longo dos últimos anos. Ainda, para avaliar o método empregado no tratamento do lixiviado proveniente das células do aterro, calculou-se os valores médios para cada parâmetro analisado, bem como os valores máximos referentes ao efluente bruto e tratado. A partir disso, determinou-se a eficiência média de redução da concentração de cada parâmetro. Ainda, comparou-se os resultados do efluente tratado com os VMPs apresentados pela Resolução 430 (CONSELHO NACIONAL DO MEIO AMBIENTE, 2011) e pela Resolução 355 (CONSELHO ESTADUAL DO MEIO AMBIENTE, 2017).

Os parâmetros analisados correspondem aos descritos em metodologias, de diversos países, para avaliação de lixiviados e efluentes, bem como os parâmetros estabelecidos na licença de operação do aterro, sendo eles: Alcalinidade total, Alumínio (Al), Arsênio (As), Bário (Ba), Boro (B), Cádmio (Cd), Chumbo $(\mathrm{Pb})$, Cianeto $(\mathrm{Cn})$, Cloreto $(\mathrm{Cl}-)$, Coliformes termotolerantes, Coliformes totais, Condutividade Elétrica (CE), Cromo (Cr), Cromo Hexavalente
(Cr VI), Demanda Bioquímica de Oxigênio (DBO5), Demanda Química de Oxigênio (DQO), Ferro (Fe), Fósforo total (P), Magnésio $(\mathrm{Mg})$, Manganês (Mn), Mercúrio (Hg), Níquel (Ni), Nitrato (NO3-), Nitrito (NO2-), Nitrogênio Amoniacal (NH3), Nitrogênio Total Kjeldahl (NTK), Oxigênio dissolvido (OD), Óleos e Graxas totais, pH, Potássio (K), Sódio $(\mathrm{Na})$, Sólidos Sedimentáveis (SS), Sólidos Suspensos Totais (SST), Sulfato (SO42-),, Temperatura (T Co), Turbidez e Zinco (Zn). Todos estes parâmetros foram analisados conforme a metodologia "Standard Methods for the examination of water and wastewater" (AMERICAN PUBLIC HEALTH ASSOCIATION, 2005, 2012).

\section{ÁGUA DOS POÇOS DE MONITORAMENTO}

O aterro sanitário atualmente dispóe de 6 poços de monitoramento de água subterrânea, sendo um localizado à montante das células (PM4) e os demais distribuídos à jusante (PJ1, PJ2, PJ3, PJ5 e PJ6) (Figura 2). Com a finalidade de realizar o estudo hidrogeológico da área, de forma a verificar se a localização dos poços em relação às células de disposição está de acordo com o sentido do fluxo subterrâneo, fez-se necessário a obtenção dos dados de cota, profundidade e nível de água. A partir dessas informaçóes, realizou-se o cálculo da carga hidráulica para cada poço e construiu-se o mapa de fluxo subterrâneo.

\section{Estudo do fluxo}

Para elaboração do mapa piezométrico, fez-se necessário calcular a carga hidráulica para cada poço de monitoramento. Levou-se em consideração a Equação 1, obtida a partir do princípio de Bernoulli, para o cálculo da carga hidráulica:

$h=\frac{p}{\rho g}+z$

Sabendo que a água subterrânea monitorada está localizada na forma de lençol freático, o termo de pressão $\left(\frac{p}{\rho g}\right)$ na equação acima é nulo e, portanto, a carga hidráulica passa a ser descrita pela Equação 2:

$h=z$ 
Em que:

$z$ é a carga de elevação da água com relação ao nível do mar. Assim, a partir das mediçôes de nível realizadas nos poços de monitoramento, calculou-se a carga hidráulica para cada um dos poços.

A partir do cálculo das cargas hidráulicas dos poços de monitoramento foi possível inferir o sentido do fluxo de água subterrânea. A elaboração do mapa potenciométrico da área e a indicação do possível fluxo da água subterrânea foi realizada com auxílio do software Arcgis ${ }^{\oplus}$, versão (10.4.1).

A partir desses valores e do shapefile referente a área do aterro importados para o software, interpolou-se os valores de carga hidráulica para toda a área. Com a finalidade de criar o mapa de fluxo a partir da ferramenta disponibilizada pelo software, alguns valores referentes às características hidrogeológicas do local foram necessários. Esses parâmetros foram transformados em informaçóes raster, que abrangem a totalidade da área de estudo. Os valores utilizados são referentes à formação do Aquífero da Serra Geral que abrange a área do aterro (Quadro 1).

\section{Amostragem e análise da água subterrânea}

Para a avaliação da qualidade da água dos poços de monitoramento, fez-se o levantamento das informaçóes dos laudos técnicos de análises da qualidade da água, realizada entre o período de 2010 a 2017 . Até o ano de 2013, o empreendimento contava com 4 poços de monitoramento. A partir desse ano, foram instalados 2 novos poços, totalizando um montante de 6 , sendo 1 localizado a montante e, os demais, a jusante (Figura 2).

Para verificação da qualidade da água monitorada através dos poços, foi realizado a comparação com os VMPs da Resolução (CONSELHO NACIONAL DO MEIO AMBIENTE, 2008), que estabelece parâmetros para enquadramento de água subterrânea, classe 2, e da Portaria 2.914 (BRASIL, 2011b) que

Quadro 1. Parâmetros hidrogeológicos referentes à formação do Aquífero da Serra Geral.

\begin{tabular}{|c|c|}
\hline Porosidade & $2,5 \%$ \\
\hline Espessura saturada & $600 \mathrm{~m}$ \\
\hline Transmissividade & $0,00116 \mathrm{~m}^{2} / \mathrm{s}$ \\
\hline
\end{tabular}

Fonte: Universidade Estadual Paulista (2000). trata sobre o padrão de potabilidade e a qualidade de água para consumo humano. $\mathrm{O}$ uso preponderante considerado foi para consumo humano, visto que, a região é predominantemente agrícola e é comum a utilização de poços para o abastecimento de água dessa população.

Os parâmetros presentes nos dados históricos analisados foram: Alcalinidade Total, Alumínio, Arsênio, Bário, Boro, Cádmio, Chumbo, Cloretos, Coliformes Termotolerantes, Coliformes Totais, Condutividade Elétrica, Cromo Hexavalente, Cromo Total, $\mathrm{DBO}_{5}$, DQO, Fósforo total, Manganês, Mercúrio, Níquel, Nitrato, Nitrito, Oxigênio Dissolvido, Óleos e Graxas totais, $\mathrm{pH}$, Sólidos Dissolvidos Totais, Sólidos Totais, Sulfato, Sulfeto, Temperatura, Turbidez e Zinco. Os referidos parâmetros foram analisados segundo a metodologia "Standard Methods for the examination of water and wastewater" (AMERICAN PUBLIC HEALTH ASSOCIATION, 2005, 2012).

Os resultados foram avaliados obtendo-se os valores máximos e a média de cada parâmetro avaliado nas amostras de cada poço de monitoramento.

A fim de se obter maiores informaçóes sobre os poços a jusante e montante, todos os dados foram avaliados, estatisticamente, através da comparação de médias (Teste t de Student), para assim indicar quais os parâmetros apresentaram variação significativa. A estatística T para todos os parâmetros, com exceção do pH, é definida pela Equação 3 (ASSOCIAÇÃO BRASILEIRA DE NORMAS TÉCNICAS, 1987).

$$
t^{*}=\frac{\overline{X_{m}}-\overline{X_{b}}}{\sqrt{\frac{S_{m}^{2}}{N_{m}}+\frac{S_{b}^{2}}{N_{b}}}}
$$

Em que:

$\mathrm{t}^{*}=$ comparação entre duas amostras

$\mathrm{X}_{\mathrm{m}}=$ média aritmética dos valores do parâmetro no poço a ser comparado

$\mathrm{X}_{\mathrm{b}}=$ média aritmética dos valores naturais (obtidos nos poços de montante)

$\mathrm{S}_{\mathrm{m}}{ }^{2}=$ variância dos valores do parâmetro no poço a ser comparado

$\mathrm{S}_{\mathrm{b}}{ }^{2}=$ variância dos valores naturais (obtidos nos poços de montante)

$\mathrm{N}_{\mathrm{m}}$ = número de observaçóes do parâmetro no poço a ser comparado 
$\mathrm{N}_{\mathrm{b}}$ = número de observaçóes dos valores naturais (obtidos nos poços de montante)

O t crítico $\left(\mathrm{t}_{\mathrm{c}}\right)$ é calculado por (Equação 4):

$t_{c}=\frac{\left(W_{b} t_{b}+W_{m} t_{m}\right)}{\left(W_{b}+W_{m}\right)}$

Em que:

$$
W_{m}=\frac{S_{m}^{2}}{N_{m}} W_{b}=\frac{S_{b}^{2}}{N_{b}}
$$

\section{Sendo:}

$\mathrm{t}_{\mathrm{b}}=$ valor tabelado de $\mathrm{t}$ (monocaudal) para $\mathrm{Nb}-1$

graus de liberdade e 0,05 de nível de significância relativa ao poço montante $\mathrm{t}_{\mathrm{m}}=$ valor tabelado de $\mathrm{t}$ (monocaudal) para $\mathrm{Nm}-1$ graus de liberdade e 0,05 de nível de significância relativa ao poço jusante a ser comparado

$\mathrm{O}$ único parâmetro que não se aplicou o teste t é o $\mathrm{pH}$, pois é bicaudal. Após o cálculo, caso o fator $\mathrm{t}^{*}$ for igual ou maior que $t_{c}$, existe então a possibilidade de aumento significativo no respectivo parâmetro.

\section{RESULTADOS E DISCUSSÃO}

\section{EFICIÊNCIA DO TRATAMENTO DE LIXIVIADO}

$\mathrm{Na}$ Tabela 1 é apresentada a quantificação dos parâmetros físico-químicos avaliados. Pode-se observar que, para a maioria dos parâmetros, o tratamento

Tabela 1. Parâmetros avaliados para o efluente bruto e tratado e respectivos VMPs

\begin{tabular}{|c|c|c|c|c|c|c|c|c|}
\hline \multirow{2}{*}{ Parâmetros } & \multicolumn{3}{|c|}{ BRUTO } & \multicolumn{3}{|c|}{ TRATADO } & \multirow{2}{*}{$\begin{array}{c}\begin{array}{c}\text { Eficiência } \\
(\%)\end{array} \\
\end{array}$} & \multirow{2}{*}{ VMP } \\
\hline & Méd. & Máx. & $\mathrm{DP}^{3}$ & Méd. & Máx. & $\mathrm{DP}^{3}$ & & \\
\hline $\mathrm{Al}(\mathrm{mg} / \mathrm{L})$ & 2,144 & 10,200 & 2,855 & 0,548 & 1,550 & 0,545 & 74,44 & 10 \\
\hline As $(\mathrm{mg} / \mathrm{L})$ & 0,00000 & 0,00643 & 0,0000 & 0,00070 & 0,00349 & 0,00156 & 45,72 & 0,1 \\
\hline $\mathrm{Ba}(\mathrm{mg} / \mathrm{L})$ & 0,206 & 0,300 & 0,057 & 0,136 & 0,300 & 0,095 & 33,66 & 5 \\
\hline $\mathrm{B}(\mathrm{mg} / \mathrm{L})$ & 0,68 & 1,95 & 0,75 & 0,19 & 0,33 & 0,12 & 71,42 & 5 \\
\hline $\mathrm{Cd}(\mathrm{mg} / \mathrm{L})$ & 0,0001 & 0,0015 & 0,0004 & 0,0001 & 0,0015 & 0,0004 & 0,00 & 0,1 \\
\hline $\mathrm{Pb}(\mathrm{mg} / \mathrm{L})$ & 0,085 & 0,516 & 0,131 & 0,01 & 0,106 & 0,030 & 83,19 & 0,2 \\
\hline $\mathrm{Cn}(\mathrm{mg} / \mathrm{L})$ & 0,272 & 1,400 & 0,521 & 0,004 & 0,031 & 0,011 & 98,58 & 0,2 \\
\hline $\mathrm{Cl}^{-}(\mathrm{mg} / \mathrm{L})$ & 1113 & 2239 & 478 & 381 & 1686 & 357 & 65,77 & 250 \\
\hline $\mathrm{CE}(\mu \mathrm{S} / \mathrm{cm})$ & 10656 & 18880 & 4658 & 2618 & 14498 & 3124 & 75,43 & $\mathrm{NE}^{2}$ \\
\hline Col. term. (NMP/100 mL) & 173497 & 1200000 & 316593 & 55185 & 570000 & 128547 & 68,19 & $10^{5}$ \\
\hline Col. tot. (NMP/100 mL) & 157518 & 1440000 & 356827 & 21052 & 83000 & 22342 & 86,63 & $\mathrm{NE}$ \\
\hline $\mathrm{Cr}$ VI $(\mathrm{mg} / \mathrm{L})$ & 0,000 & 0,000 & 0,000 & 0,009 & 0,043 & 0,019 & 0 & 0,1 \\
\hline Cr total $(\mathrm{mg} / \mathrm{L})$ & 1,339 & 27,400 & 5,433 & 0,033 & 0,144 & 0,040 & 97,52 & 0,5 \\
\hline $\mathrm{DBO}(\mathrm{mg} / \mathrm{L})$ & 518 & 1675 & 484 & 75 & 200 & 54 & 85,58 & 120 \\
\hline DQO $(\mathrm{mg} / \mathrm{L})$ & 2233 & 7752 & 1661 & 376 & 792 & 155 & 83,14 & 330 \\
\hline $\mathrm{Fe}(\mathrm{mg} / \mathrm{L})$ & 18,075 & 68,100 & 15,356 & 3,927 & 11,100 & 2,553 & 78,27 & 10 \\
\hline $\mathrm{P}(\mathrm{mg} / \mathrm{L})$ & 6,22 & 19,00 & 4,78 & 0,74 & 1,81 & 0,49 & 88,08 & 4 \\
\hline $\mathrm{Mg}(\mathrm{mg} / \mathrm{L})$ & 40,217 & 139,000 & 32,708 & 12,664 & 26,800 & 5,879 & 68,51 & $\mathrm{NE}$ \\
\hline $\mathrm{Mn}(\mathrm{mg} / \mathrm{L})$ & 1,932 & 7,750 & 2,209 & 0,983 & 1,770 & 0,462 & 49,10 & 1 \\
\hline $\mathrm{Hg}(\mathrm{mg} / \mathrm{L})$ & 0,00000 & 0,00000 & 0,00000 & 0,00001 & 0,00024 & 0,00005 & 0 & 0,01 \\
\hline $\mathrm{Ni}(\mathrm{mg} / \mathrm{L})$ & 0,059 & 0,226 & 0,058 & 0,014 & 0,037 & 0,011 & 76,47 & 1 \\
\hline $\mathrm{NO}_{3-}(\mathrm{mg} / \mathrm{L})$ & 3,14 & 8,57 & 3,80 & 0,58 & 1,04 & 0,36 & 81,43 & $\mathrm{NE}$ \\
\hline
\end{tabular}

${ }^{1}$ VMP: Valor máximo permitido conforme Resoluções CONAMA 430/2011 e CONSEMA 355/2017

${ }^{2} \mathrm{NE}$ : Não especificados em resolução

${ }^{3}$ DP: Desvio Padrão 
Tabela 1. Continuação...

\begin{tabular}{|c|c|c|c|c|c|c|c|c|}
\hline \multirow{2}{*}{ Parâmetros } & \multicolumn{3}{|c|}{ BRUTO } & \multicolumn{3}{|c|}{ TRATADO } & \multirow{2}{*}{$\begin{array}{c}\text { Eficiência } \\
(\%)\end{array}$} & \multirow{2}{*}{$\mathrm{VMP}^{1}$} \\
\hline & Méd. & Máx. & $\mathrm{DP}^{3}$ & Méd. & Máx. & $\mathrm{DP}^{3}$ & & \\
\hline $\mathrm{NO}_{2}(\mathrm{mg} / \mathrm{L})$ & 0,06 & 0,22 & 0,09 & 0,21 & 0,74 & 0,32 & 0 & $\mathrm{NE}$ \\
\hline $\mathrm{NH}_{3}(\mathrm{mg} / \mathrm{L})$ & 587,75 & 1127 & 357,70 & 50,74 & 113 & 31,22 & 91,37 & 20 \\
\hline NTK (mg/L) & 746,66 & 1289 & 360,84 & 68,62 & 135 & 34,02 & 90,81 & 20 \\
\hline $\mathrm{OD}(\mathrm{mg} / \mathrm{L})$ & 0,92 & 6,2 & 1,54 & 4,25 & 9,68 & 3,09 & 0 & $>0,5$ \\
\hline Óleos e Graxas totais $(\mathrm{mg} / \mathrm{L})$ & 0,20 & 1 & 0,45 & 6,70 & 27,2 & 11,78 & 0 & 60 \\
\hline $\mathrm{pH}$ & 7,52 & 8,4 & 1,00 & 7,80 & 8,5 & 0,52 & 0 & $6-9$ \\
\hline $\mathrm{K}(\mathrm{mg} / \mathrm{L})$ & 551,9 & 1063,0 & 291,9 & 134,9 & 262,0 & 71,4 & 75,55 & $\mathrm{NE}$ \\
\hline $\mathrm{Na}(\mathrm{mg} / \mathrm{L})$ & 775,8 & 1920,0 & 469,0 & 169,2 & 330,0 & 92,2 & 78,19 & 200 \\
\hline $\mathrm{SS}(\mathrm{mL} / \mathrm{L})$ & 0,1 & 1,5 & 0,3 & 0,9 & 11,0 & 2,4 & 0 & 1 \\
\hline SST (mL/L) & 536,4 & 10277,0 & 2078,3 & 126,0 & 1181,0 & 244,9 & 76,51 & 180 \\
\hline $\mathrm{SO}_{4}^{2-}(\mathrm{mg} / \mathrm{L})$ & 93,20 & 752,00 & 199,73 & 17,91 & 100,00 & 31,67 & 80,78 & 1000 \\
\hline $\mathrm{T}\left({ }^{\circ} \mathrm{C}\right)$ & 22 & 30 & 6 & 22 & 32 & 6 & - & $<40$ \\
\hline Turbidez (UTN) & 332 & 976 & 433 & 420 & 1626 & 676 & 0 & $\mathrm{NE}$ \\
\hline Zn (mg/L) & 1,097 & 3,957 & 1,325 & 0,132 & 0,440 & 0,139 & 88,01 & 2 \\
\hline
\end{tabular}

${ }^{1}$ VMP: Valor máximo permitido conforme Resoluções CONAMA 430/2011 e CONSEMA 355/2017

${ }^{2} \mathrm{NE}$ : Não especificados em resolução

${ }^{3}$ DP: Desvio Padrão

mostra-se eficiente e atende aos parâmetros estabelecidos pelas Resoluçóes 430 (CONSELHO NACIONAL DO MEIO AMBIENTE, 2011) e CONSEMA 355/2017 (CONSELHO ESTADUAL DO MEIO AMBIENTE, 2017). Contudo, o tratamento apresentou baixa eficiência, de acordo com o valor de eficiência média calculada com base nas concentraçóes do efluente bruto e tratado, para nitritos, óleos e graxas e sólidos sedimentáveis. Apesar de tudo, as médias e desvios padrão para cada parâmetro decresceram, em sua maioria, indicando que os valores das concentraçôes do efluente após o tratamento apresentam um menor grau de dispersão. Verificou-se, ainda, uma eficiência de tratamento média de $60 \%$.

Embora o tratamento não seja eficiente para a redução das concentraçóes de certos parâmetros, sua eficiência já pode ser considerada razoável, visto que, no país, o tratamento de lixiviados em aterros sanitários é ainda considerado um grande problema em decorrência de sua complexidade e elevado custo. De acordo com Contrera et al. (2014), uma prática muito comum adotada no Brasil é o transporte do lixiviado gerado até as plantas de tratamento de esgoto doméstico existentes, essas que, muitas vezes, não são projetadas para o tratamento de substâncias específicas presentes nesse tipo de composto. Já de acordo com Castilhos Junior et al. (2009), outros sistemas amplamente utilizados para tratamento de lixiviados são os sistemas biológicos, como lagoas em série (anaeróbias, facultativas, maturação), em que ocorre a remoção do material orgânico e inorgânico por meio da atividade de bactérias e fitoplâncton. Porém, ainda de acordo com os autores, relata-se, na literatura, problemas relacionados a esses sistemas, uma vez que eles apresentam certa dificuldade em remover compostos recalcitrantes, que resultam em uma elevada DQO, bem como na remoção de amônia. Outros estudos, como o de Contrera, Zaiat e Schalch (2006), avaliaram a possibilidade a utilização de reatores anaeróbios, contudo, apontou-se que esse processo apenas é eficiente para o tratamento de lixiviados considerados jovens, isto é, concentraçóes relativamente baixas de nitrogênio amoniacal, altas concentraçóes de ácidos voláteis e elevada relação DBO/DQO. Nesse contexto, ainda se verifica a necessidade de estudos e desenvolvimento de processos de tratamento que sejam viáveis tanto técnica, quanto economicamente, de forma a promover uma universalização da implantação de sistemas de tratamento de lixiviado que sejam realmente eficazes e eficientes, que reduzam a carga 
de poluentes até atingir os valores apresentados em legislação, e possibilitando o lançamento em corpos hídricos sem causar danos ambientais.

A partir da Figura 4 pode-se perceber que, no efluente tratado, as concentraçóes de nitrito são mais elevadas quando comparadas com o efluente bruto. Isso indica ocorrência predominante de reaçóes de nitritação ao longo do tratamento, isto é, fase em que as bactérias oxidadoras de amônia do gênero Nitrossomas transformam o nitrogênio amoniacal em nitrito. Outras fases de degradação do nitrogênio, como a nitratação, em que as bactérias oxidadoras de nitrito do gênero Nitrobacter transformam nitrito a nitrato (ZILZ; SILVA; PINHEIRO, 2014), não se mostram tão expressivas (Figura 5). Tal fato evidencia-se no mês de maio de 2016, em que se verifica as maiores concentraçóes de nitrito no efluente tratado (Figura 4). Quanto ao nitrogênio amoniacal (Figura 6), verifica-se que ocorre uma redução significativa em sua concentração após o tratamento, sendo transformado em nitritos e nitratos a partir dos processos de degradação do nitrogênio. Contudo, seus valores ainda permanecem acima do VMP (20 mg/L), indicando uma deficiência na forma de tratamento. De acordo com Wang et al. (2008), altas concentraçôes nitrogênio amoniacal são observadas em aterros sanitários com tempo de funcionamento acima de 5 anos e, por conta disso, acabam por acarretar em uma sobrecarga no sistema de tratamento biológico, além de desequilibrar o balanço entre a disponibilidade de carbono e nitrogênio, resultando em excesso de amônia livre e podendo inibir a ação de microrganismos. Além disso, as significativas oscilaçóes observadas no comportamento do oxigênio dissolvido (Figura 7) podem estar exercendo influência sobre as taxas de degradação desses parâmetros, visto que o processo de degradação de nitrogênio é fortemente influenciado pelas concentraçôes de oxigênio dissolvido existentes no sistema (ZOPPAS; BERNARDES; MENEGUZZI, 2016).

Foram observadas maiores concentraçóes de sólidos sedimentáveis no efluente tratado do que no efluente bruto, em diversos meses, ultrapassando, em alguns casos, o VMP (Figura 8). A variação da concentração desses sólidos pode também estar relacionada com o tempo necessário para decantação desses quando são encaminhados para o banhado construído, bem

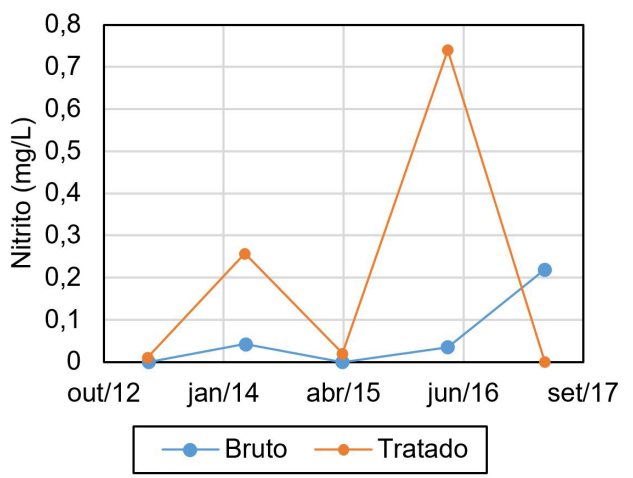

Figura 4: Concentração de nitrito no efluente bruto e tratado.

Fonte: Elaborado pelos autores.

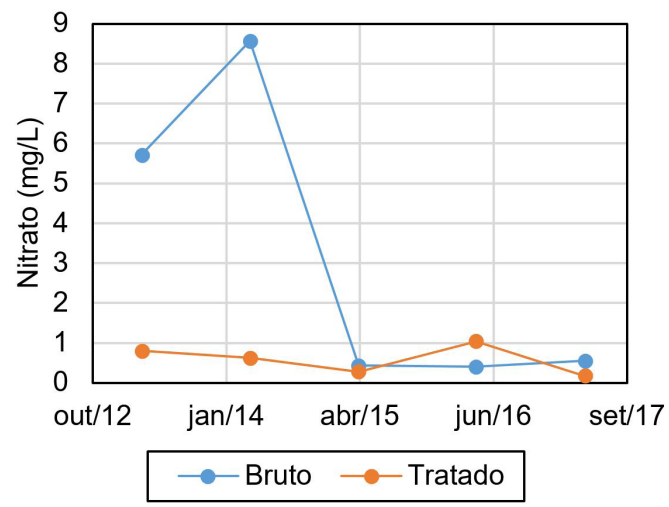

Figura 5: Concentração de nitrato no efluente bruto e tratado.

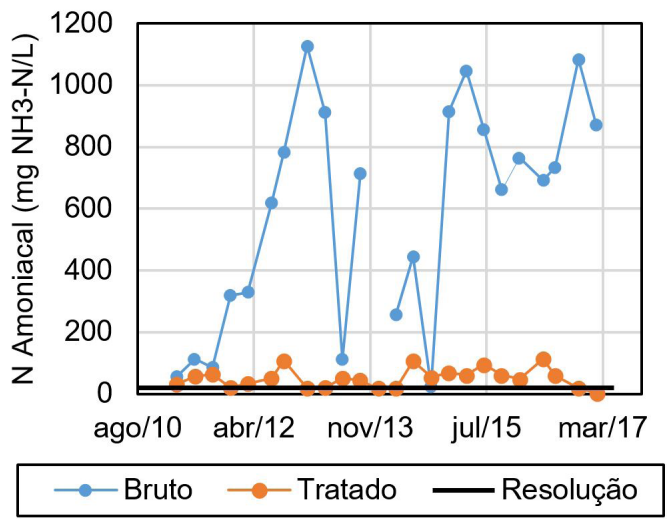

Figura 6: Concentração de nitrogênio amoniacal no efluente bruto e tratado. 
como relacionada com a condição meteorológica do período de análise, em que, períodos muito chuvosos podem ter acarretado em maior diluição e, portanto, menores concentraçóes, sendo a situação contrária também válida. Da mesma forma, a ineficiência média do parâmetro de turbidez pode estar relacionada com a formação dos sólidos sedimentáveis em alguns períodos (Figura 9). Uma comparação direta entre os parâmetros não pode ser realizada visto que a avaliação do parâmetro turbidez foi executada anualmente.

No que se refere a DBO5 e DQO, embora a eficiência média de remoção seja elevada (85,58\% e 83,14\%, respectivamente), tais parâmetros ainda ficam, em alguns meses, acima do VMP segundo a resolução CONSEMA 355/2017 (CONSELHO ESTADUAL DO MEIO AMBIENTE, 2017), especialmente quando trata-se da DQO (Figuras 10 e 11). Isso é indicativo de que o sistema de tratamento é capaz de remover os compostos biodegradáveis, porém não é capaz de reduzir a concentração de compostos recalcitrantes ao valor limite. $\mathrm{O}$ índice de biodegrabilidade (DBO5/DQO) médio do lixiviado coletado para tratamento é de, aproximadamente, 0,23 , demonstrando a elevada presença de substâncias não degradáveis biologicamente. As elevadas concentraçóes de DQO podem ser resultantes das elevadas concentraçóes de cloretos, também observadas e que ultrapassam o VMP (Figura 12) (KJELDSEN et al., 2002).

Quanto ao parâmetro óleos e graxas, embora se tenha observado uma ineficiência no tratamento e um aumento da concentração média, pode-se verificar que os valores não ultrapassam o VMP (Figura 13). $\mathrm{O}$ valor máximo encontrado $(27,2 \mathrm{mg} / \mathrm{L})$ pode ser decorrente de alguma anomalia ocorrida no período visto que, nos demais meses analisados, os valores são baixos e até mesmo nulos.

\section{FLUXO SUBTERRÂNEO}

A Tabela 2 apresenta as informaçôes de cota, profundidade e nível de água medidas em cada um dos poços presentes no aterro sanitário, bem como a sequência de cálculo para a obtenção das cargas hidráulicas. Estes dados possibilitaram a elaboração do mapa piezométrico e, a partir deste, identificou-se o comportamento hidrogeológico da área.

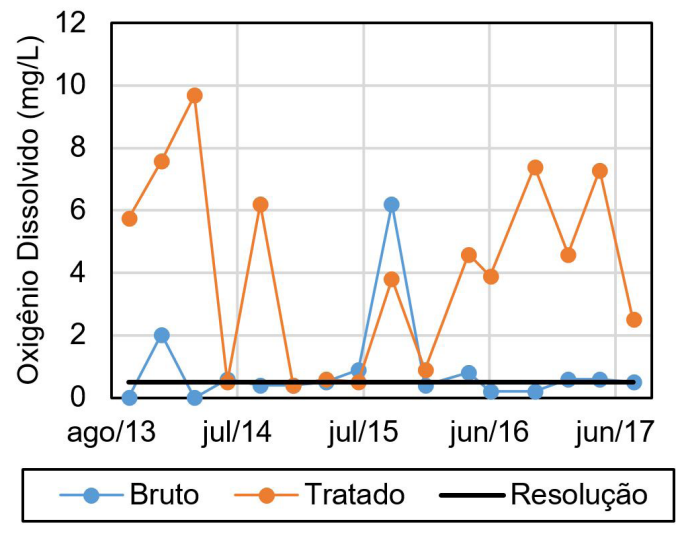

Figura 7: Concentração de oxigênio dissolvido no efluente bruto e tratado.

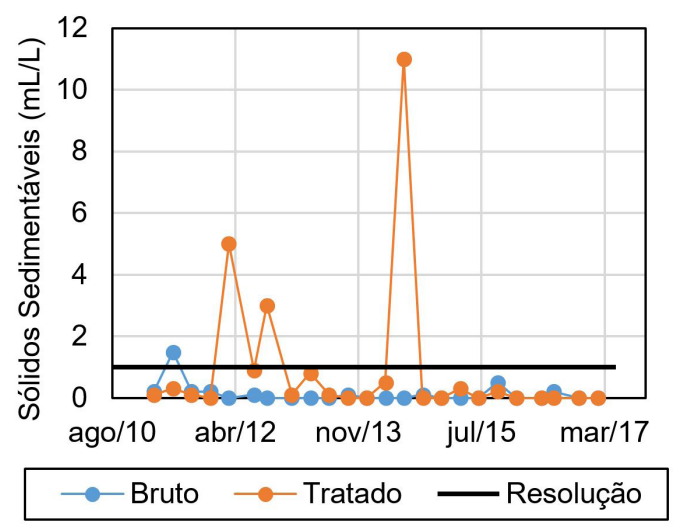

Figura 8: Concentração de sólidos sedimentáveis no efluente bruto e tratado.

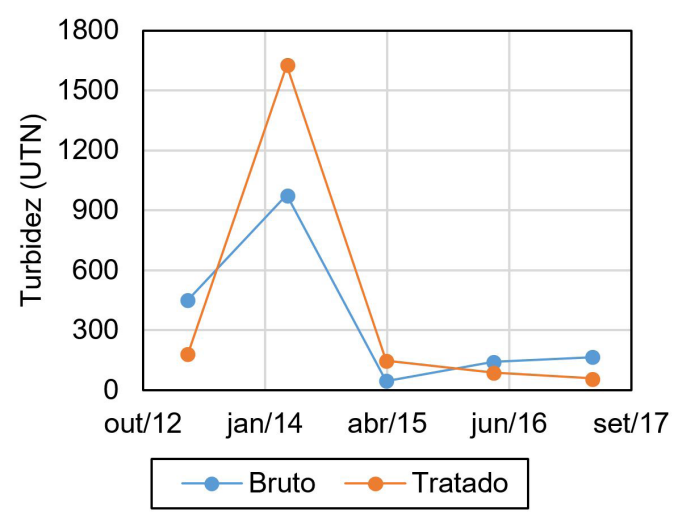

Figura 9: Parâmetro turbidez no efluente bruto e tratado. 


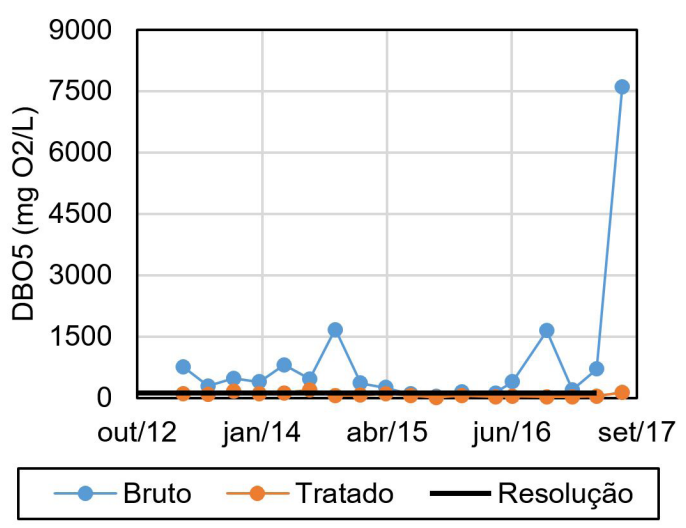

Figura 10: $\mathrm{DBO}_{5}$ no efluente bruto e tratado.

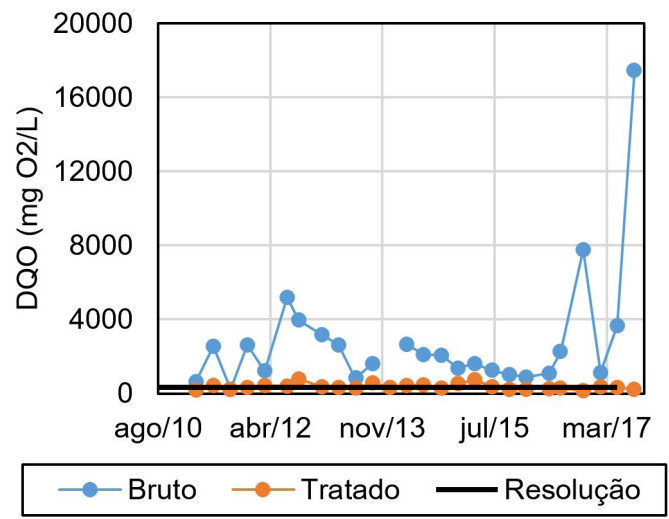

Figura 11: DQO no efluente bruto e tratado.

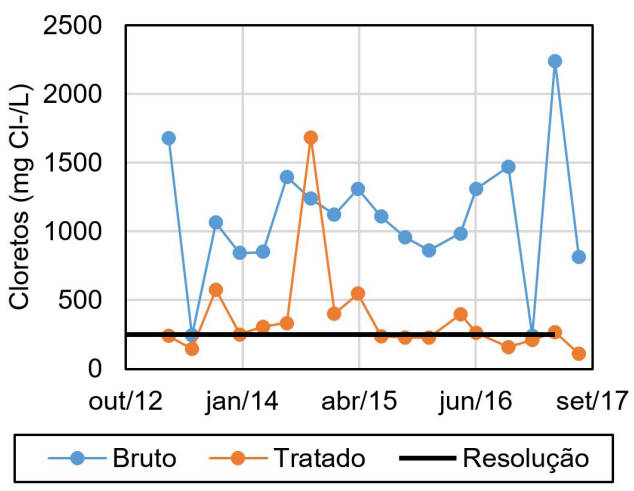

Figura 12: Concentração de cloretos no efluente bruto e tratado.

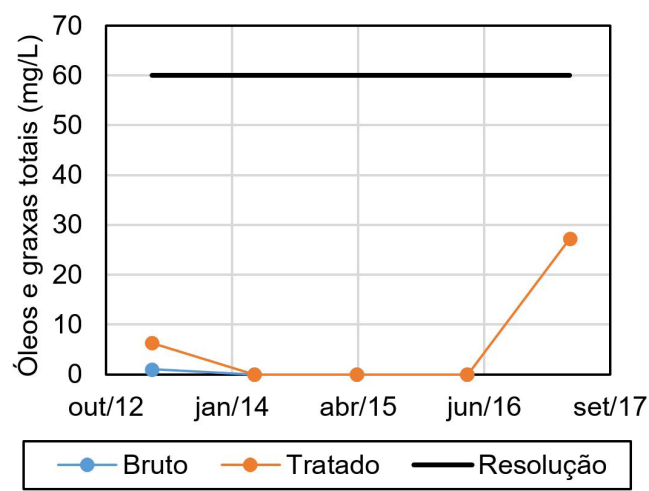

Figura 13: Concentração de óleos e graxas totais no efluente bruto e tratado.

Tabela 2. Dados medidos determinação da carga hidráulicas para os poços de monitoramento

\begin{tabular}{|c|c|c|c|c|c|c|}
\hline Poço & Coordenadas & Cota $(\mathrm{m})$ & $\begin{array}{l}\text { Profundidade } \\
\qquad(\mathrm{m})\end{array}$ & $\begin{array}{c}\text { Presença de } \\
\text { água (m) }\end{array}$ & $\begin{array}{c}\text { Cota do } \\
\text { fundo do poço } \\
\text { (cota - profundidade) } \\
(\mathrm{m})\end{array}$ & $\begin{array}{c}\mathrm{h}=\mathrm{z}=\text { cota do fundo } \\
\text { do poço }+ \text { nível de } \\
\text { água }(\mathrm{m})\end{array}$ \\
\hline \multirow{2}{*}{ PJ1 } & $27^{\circ} 52^{\prime} 06,51^{\prime \prime S}$ & \multirow{2}{*}{568,7} & \multirow{2}{*}{8,2} & \multirow{2}{*}{4,00} & \multirow{2}{*}{560,5} & \multirow{2}{*}{564,5} \\
\hline & $53^{\circ} 14^{\prime} 27,12^{\prime \prime} \mathrm{O}$ & & & & & \\
\hline \multirow{2}{*}{ PJ2 } & 27०52'04,38”S & \multirow{2}{*}{568,6} & \multirow{2}{*}{8,0} & \multirow{2}{*}{4,00} & \multirow{2}{*}{560,6} & \multirow{2}{*}{564,6} \\
\hline & $53^{\circ} 14^{\prime} 28,32^{\prime \prime} \mathrm{O}$ & & & & & \\
\hline \multirow{2}{*}{ PJ3 } & 27'52'04,39"S & \multirow{2}{*}{564,8} & \multirow{2}{*}{8,5} & \multirow{2}{*}{2,10} & \multirow{2}{*}{556,3} & \multirow{2}{*}{558,4} \\
\hline & $53^{\circ} 14^{\prime} 26,92^{\prime \prime O}$ & & & & & \\
\hline \multirow{2}{*}{ PM4 } & 27’52’266”S & \multirow{2}{*}{596,8} & \multirow{2}{*}{8,1} & \multirow{2}{*}{3,70} & \multirow{2}{*}{588,7} & \multirow{2}{*}{592,4} \\
\hline & $53^{\circ} 14^{\prime} 63,40 " \mathrm{O}$ & & & & & \\
\hline \multirow{2}{*}{ PJ5 } & 27०52'12,40”S & \multirow{2}{*}{588,0} & \multirow{2}{*}{7,0} & \multirow{2}{*}{0,50} & \multirow{2}{*}{581,0} & \multirow{2}{*}{581,5} \\
\hline & $53^{\circ} 14^{\prime} 27,30^{\prime \prime O}$ & & & & & \\
\hline \multirow{2}{*}{ PJ6 } & 27०52'11,70"S & \multirow{2}{*}{587,0} & \multirow{2}{*}{7,6} & \multirow{2}{*}{0,15} & \multirow{2}{*}{579,4} & \multirow{2}{*}{579,6} \\
\hline & $53^{\circ} 14^{\prime} 27,00^{\prime \prime} \mathrm{O}$ & & & & & \\
\hline
\end{tabular}

${ }^{*} \mathrm{~J}$ - Jusante; M - Montante. 
A partir do mapa de fluxo (Figura 14), é possível perceber que os poços estáo localizados adequadamente, no que se refere à identificação de poço a montante e poços a jusante, uma vez que o poço a montante apresenta a maior carga hidráulica com relação aos demais pontos da área de interesse. Diante disso, torna-se possível avaliar de forma mais consistente, a partir dos dados históricos das amostras de água para cada poço, qual é a interferência da presença do aterro sanitário sobre a qualidade da água subterrânea. Contudo, visto a presença de uma lâmina de água rasa, bem como as profundidades de instalação dos poços de monitoramento serem consideradas baixas, uma contaminação de água mais acentuada pode, por muitas vezes, ser subavaliada, já que a pluma de contaminação pode ter atingindo maiores profundidades. Diante disso, a utilização de poços rasos para a avaliação de possíveis contaminaçôes por lixiviados de aterros sanitários pode não representar cenários mais extremos, impedindo que medidas de intervenção sejam tomadas pela falta de conhecimento do real problema. Uma alternativa refere-se à utilização de poços multiníveis, que permitem uma amostragem de concentraçóes em diferentes profundidades do lençol freático.

\section{QUALIDADE DA ÁGUA SUBTERRÂNEA}

Na Tabela 1-A estão expostos os resultados da estatística descritiva dos parâmetros considerados na qualificação da água subterrânea. Em geral, pode-se observar que a média e o desvio padrão não apresentaram expressivas oscilações entre os diferentes poços à jusante e com o de montante, entretanto, verificou-se expressivas oscilaçóes nos parâmetros coliformes termotolerantes, coliformes totais e sólidos totais. Os parâmetros avaliados e que apresentam VMP em alguma das legislaçóes são $\mathrm{pH}$, cádmio, chumbo, cloretos, coliformes totais e termotolerantes, cromo total, mercúrio, níquel, sólidos dissolvidos totais e

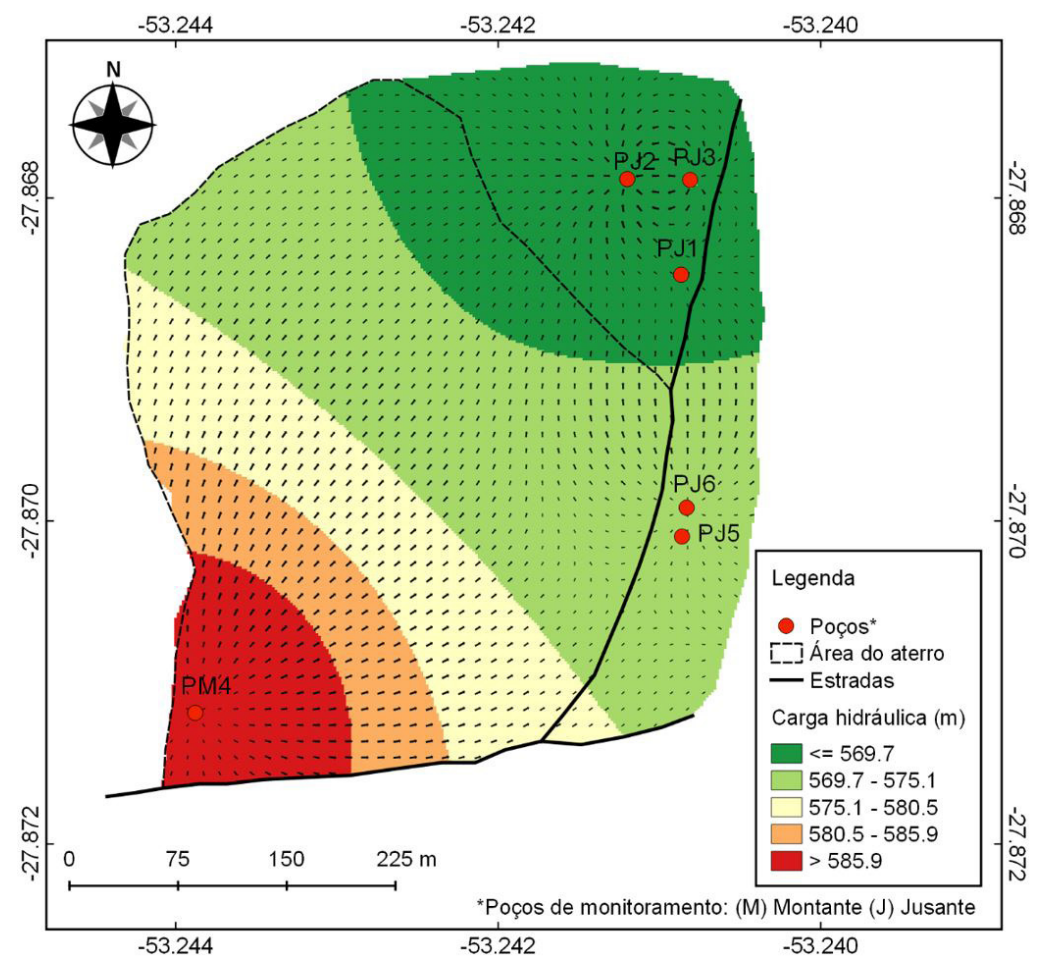

Figura 14. Fluxo da água subterrânea sob o aterro sanitário de Palmeira das Missões. 
sulfatos. Os VMPs para cada um desses parâmetros são apresentados no Quadro 2.

A concentração máxima de chumbo (Figura 15) excedeu os limites previstos $(>0,01 \mathrm{mg} / \mathrm{L})$ em todos os poços a jusante, e em termos de valor médio, somente o poço PJ6 náo apresentou teor acima do limite máximo estabelecido $(0,01 \mathrm{mg} / \mathrm{L})$. No mês de julho/2014 observou-se os valores máximos nos poços $1(0,07 \mathrm{mg} / \mathrm{L})$ e $3(0,216 \mathrm{mg} / \mathrm{L})$, enquanto que, para os poços $2(0,02 \mathrm{mg} / \mathrm{L})$ e $5(0,015 \mathrm{mg} / \mathrm{L})$, os valores máximos ocorreram nos meses de janeiro e julho de 2015, respectivamente. Apesar do PJ6 não ter ultrapassado o limite, a maior concentração encontrada $(0,006 \mathrm{mg} / \mathrm{L})$ foi no mesmo mês que o PJ5. Como nenhuma concentração foi detectada nas amostras de água do poço à montante, pode-se inferir que a contaminaçáo deve ser proveniente do lixiviado gerado pelo aterro, uma vez que nas amostras de efluente verifica-se a presença desse elemento. Além disso, observando o mapa de fluxo subterrâneo (Figura 2), verifica-se que os pontos de menor carga hidráulica são PJ1, PJ2 e PJ3, justamente onde observou-se as maiores concentrações, indicando que a água subterrânea transporte contaminantes do lixiviado em direção à essa região. A presença de compostos de chumbo deve-se, possivelmente, à disposição indevida no aterro sanitário de baterias de chumbo, tintas de chumbo, compostos químicos utilizados durante o processamento de fotografias, tubulaçóes, dentre outros materiais produzidos com base nesse elemento

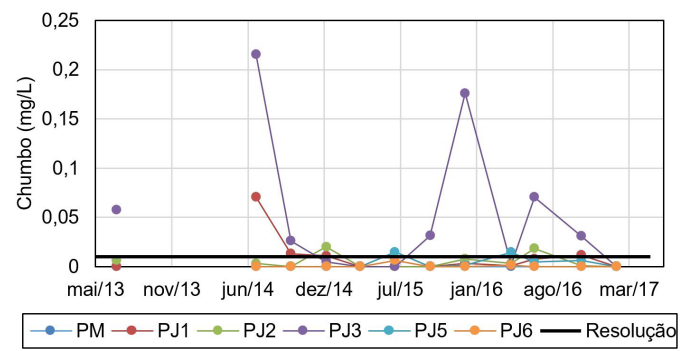

Figura 15. Concentraçóes de chumbo para as amostras de água dos poços.

Quadro 2. VMPs para os parâmetros avaliados.

\begin{tabular}{|c|c|c|}
\hline Parâmetros & $\begin{array}{c}\text { Portaria } 2.914 \\
\text { (BRASIL, 2011b) }\end{array}$ & $\begin{array}{c}\text { Resolução } 396 \\
\text { (CONSELHO NACIONAL } \\
\text { DO MEIO AMBIENTE, 2008) }\end{array}$ \\
\hline pH & $6,0-9,5$ & NR \\
\hline Alcalinidade Total (mg/L) & $\mathrm{NR}^{*}$ & NR \\
\hline Cádmio $(\mathrm{mg} / \mathrm{L})$ & 0,005 & 0,005 \\
\hline Chumbo (mg/L) & 0,01 & 0,01 \\
\hline Cloretos $(\mathrm{mg} / \mathrm{L})$ & 250 & 250 \\
\hline Coliformes Termotolerantes (NMP/100 mL) & Ausentes em $100 \mathrm{~mL}$ & Ausentes em $100 \mathrm{~mL}$ \\
\hline Coliformes Totais $(\mathrm{NMP} / 100 \mathrm{~mL})$ & Ausentes em $100 \mathrm{~mL}$ & Ausentes em $100 \mathrm{~mL}$ \\
\hline Condutividade $(\mu \mathrm{S} / \mathrm{cm})$ & NR & NR \\
\hline Cromo Total (mg/L) & 0,05 & NR \\
\hline DBO5 $(\mathrm{mg} / \mathrm{L})$ & NR & NR \\
\hline DQO (mg/L) & NR & NR \\
\hline Mercúrio (mg/L) & 0,001 & 0,001 \\
\hline Níquel $(\mathrm{mg} / \mathrm{L})$ & 0,07 & 0,02 \\
\hline Oxigênio Dissolvido (mg/L) & NR & NR \\
\hline Sólidos Dissolvidos Totais (mg/L) & 1000 & 1000 \\
\hline Sólidos Totais $(\mathrm{mg} / \mathrm{L})$ & NR & NR \\
\hline Sulfato $(\mathrm{mg} / \mathrm{L})$ & 250 & 250 \\
\hline
\end{tabular}

*NR: Não referenciado 
químico (MOR et al., 2006; MOTURI; RAWAT; SUBRAMANIAN, 2004; PANAHIFARD et al., 2017).

Com relação ao cromo total, somente o PJ3 apresentou valor acima do permitido (>0,05 mg/L). A ocorrência deu-se no mês de outubro/2014 (0,0714 $\mathrm{mg} / \mathrm{L}$ ) (Figura 16). Além, disso, o mesmo ponto apresentou a maior média da série, seguido dos poços PJ5, PJ6, PM4, PJ1 e PJ2, respectivamente. Referente ao mercúrio (Figura 17), somente o PM4 apresentou concentração superior aos valores máximos das resoluções observadas ( $>0,001 \mathrm{mg} / \mathrm{L}$ ), representando um indicativo de contaminação anterior à essa área. As concentraçóes observadas nos demais poços ficaram abaixo do limite de detecção do equipamento analítico. Para o níquel, apenas uma amostra, no PJ5 (0,087 mg/L), excedeu o VMP $(0,02 \mathrm{mg} / \mathrm{L})$, dada, possivelmente, por alguma interferência externa (Tabela 3).

Outros estudos em diferentes regióes do mundo também observaram a presença de tais metais nos lixiviados e na água subterrânea (ABD EL-SALAM; ABU-ZUID, 2015; AL SABAHI et al., 2009; BECK et al., 2010; MOR et al., 2006; MOTURI; RAWAT; SUBRAMANIAN, 2004; PANAHIFARD et al., 2017). Traços de metais estão fortemente associados com o material orgânico do lixiviado e as espécies desses variam de acordo com as condições químicas do aterro, como condiçóes de redox e pH (YOUCAI; ZIYANG, 2016), principalmente quando a disposição de resíduos ainda é recente e a fase predominante de degradação é a ácida. Nessa fase, a DQO, DBO e condutividade elétrica do lixiviado são elevadas em decorrência de dissolução de ácidos orgânicos no lixiviado, reduzindo o pH e permitindo a solubilização de metais pesados (TCHBANOGLOUS; THESSEN; VIGIL, 1994). As baixas concentrações dos metais observadas no presente estudo podem estar relacionadas ao fenômeno de atenuação que ocorre no solo, em decorrência de mecanismos geoquímicos, como processos de adsorção e precipitação química (AHARONI; SIEBNER; DAHAN, 2017; MELO et al., 2008).

Considerando os parâmetros biológicos coliformes totais e termotolerantes (Figuras 18 e 19), pode-se observar altos valores, para todos os poços. De acordo com os padróes de referência, tais parâmetros deveriam ser nulos, ou seja, ausência de coliformes em $100 \mathrm{~mL}$ de amostra. Contudo, ao avaliar as séries de dados,

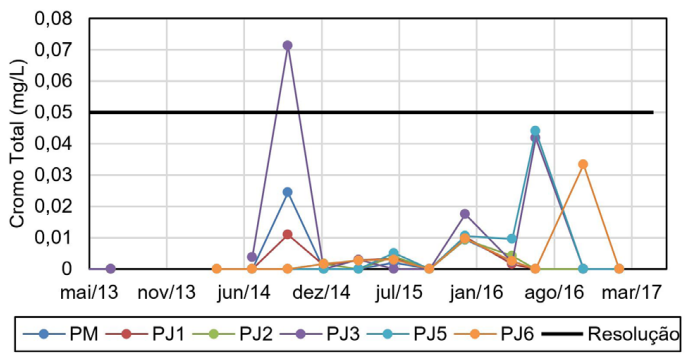

Figura 16. Concentraçóes de cromo total para as amostras de água dos poços.

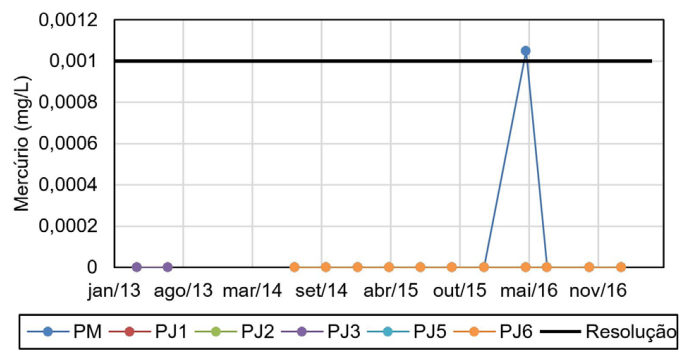

Figura 17. Concentrações de mercúrio para as amostras de água dos poços.

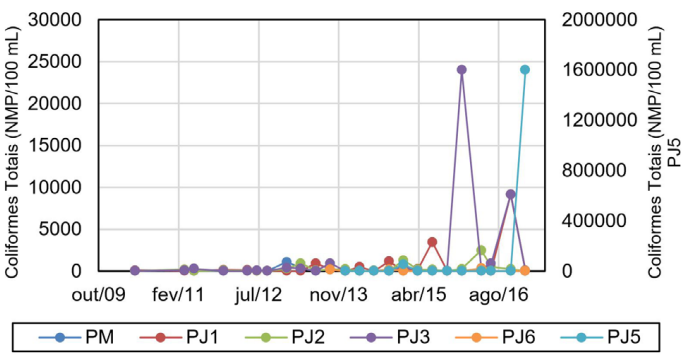

Figura 18. Coliformes totais para as amostras de água dos poços.

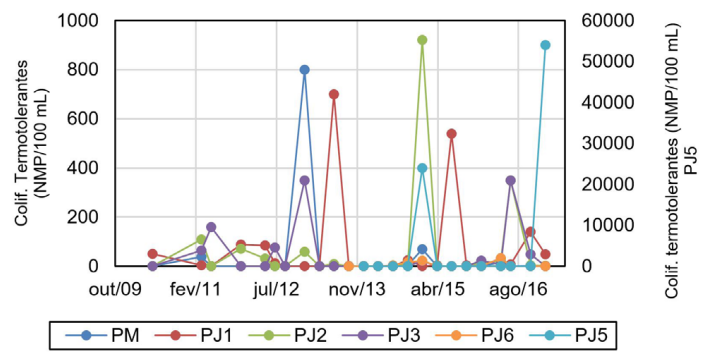

Figura 19. Coliformes termotolerantes para as amostras de água dos poços. 
pode-se identificar que, até aproximadamente o mês de abril/2014, quase todas as amostras, para todos os poços, apresentaram ausência de coliformes, tanto termotolerantes quanto totais, com exceção do mês de janeiro de 2013, em que se observou valores na ordem de centenas, indicando contaminação. A principal hipótese para essa ocorrência é de interferência externa, visto que as maiores concentraçóes foram no poço localizado a montante do aterro. Após o mês de abril/2014, verificou-se a ocorrência de períodos de oscilação no número de coliformes, porém não se observou mais nenhuma amostra com ausência (Figuras 18 e 19). Tais oscilaçôes são também visualizadas pela alta variabilidade demonstrada pelo desvio padrão dos coliformes termotolerantes e totais, conforme exposto na Tabela 3. Estes resultados indicam a contaminação da água subterrânea, essa que pode ser proveniente da ineficiência do tratamento do lixiviado e do próprio lixiviado que não é coletado nos drenos, bem como pode ser proveniente de fontes não relacionadas ao aterro, como o desenvolvimento da atividade de agropecuária, presente nessa região.

Ao observar as análises do efluente bruto e tratado (Figura 20), é possível identificar possíveis justificativas das observações levantadas anteriormente. Nos meses de outubro de 2013 e abril de 2014, por exemplo, verificou-se a ocorrência de extremos nas concentraçôes de coliformes no efluente. Apesar de tratado, as concentraçóes permaneceram altas, na ordem de milhares, conduzindo à sua percolação pelo solo e atingindo a água subterrânea.

Considerando que alguns dos parâmetros observados e que ultrapassaram os VMPs apontaram
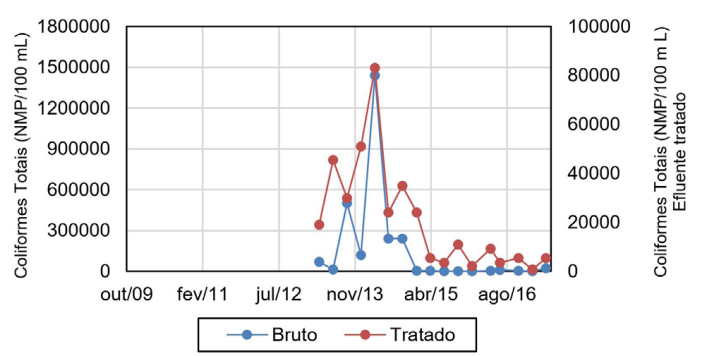

Figura 20. Concentração de coliformes totais observada no efluente bruto e tratado. a possibilidade de serem oriundos do lixiviado dos resíduos sólidos dispostos no aterro sanitário, medidas de interferência devem ser tomadas. Idealmente, a primeira ação envolveria a identificação do local que possivelmente apresenta algum tipo de vazamento de lixiviado, para o planejamento e definição das melhoras alternativas de contenção e remediação. Outra possibilidade é de que certas concentraçóes observadas sejam provenientes da última etapa de tratamento do efluente, o banhado construído, que não possui qualquer tipo de impermeabilização, permitindo que o líquido infiltre pelo solo. Além disso, verificou-se que, para o efluente tratado, alguns parâmetros ainda ultrapassaram os VMPs. Dessa forma, uma melhora no processo de tratamento de efluentes, incluindo etapas que sejam eficientes para a remoção de certos parâmetros, como alguns metais, poderia, talvez, resultar em uma melhora dos resultados de amostragem da água subterrânea. Outra hipótese que não deve ser descartada é a possibilidade de contaminação por outras fontes poluidoras, especialmente quando se trata de coliformes e quando se tem a presença de atividade agropecuária ao entorno da área do aterro sanitário.

Com relação aos demais parâmetros que possuem VMP na legislação, não se verificou valores excedentes. Embora os outros parâmetros não apresentem limites permitidos pela legislação, é importante avaliá-los, uma vez que eles também são indicadores de qualidade da água. Os valores de $\mathrm{DBO} 5$ não ultrapassaram $20 \mathrm{mgO} / \mathrm{L}$, sendo o PJ5 responsável por esse valor (Figura 21). Quanto à DQO, os valores de não ultrapassaram $60 \mathrm{mgO} 2 / \mathrm{L}$, tendo como picos os poços PJ3 e alguns meses picos no PJ5 (Figura 22).

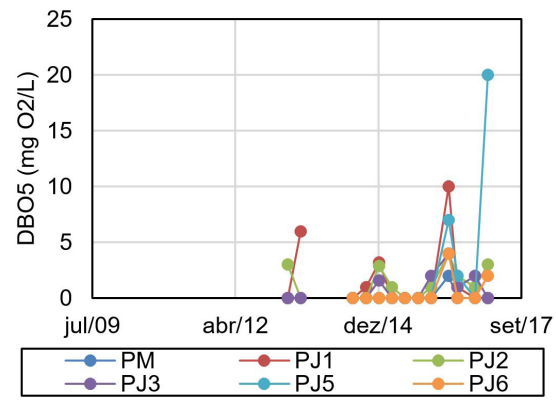

Figura 21: $\mathrm{DBO}_{5}$ para as amostras de água dos poços. 


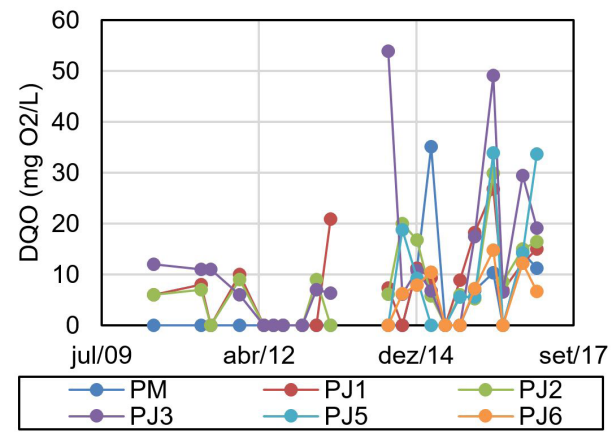

Figura 22: DBO para as amostras de água dos poços.

Para a DBO5, o poço PJ3 não apresentou valores tão altos em relação aos que foram observados para DQO, o que indica que os valores são provenientes de compostos que são difíceis de serem biodegradados. Em abril de 2015, o PM4 apresentou valores acima dos demais, indicando contaminação anterior ao poço de montante. Valores semelhantes e até maiores de DBO e DQO foram observados por El-Salam e Abu-Zuid (2015). De acordo com os autores, essas faixas representam a não ocorrência de contaminação orgânica da água subterrânea pelo lixiviado, por conta das baixas concentraçóes.

Quanto ao OD, verificou-se uma variação com amplitude significativa, partindo de concentraçóes próximas à zero em alguns meses e, em outros, concentraçóes próximas a 8-9 $\mathrm{mg} \mathrm{O}_{2} / \mathrm{L}$ (Figura 18). Rose e Long (1988) colocam que é assumido que o oxigênio derivado da atmosfera é rapidamente consumido no solo e na zona não saturada em função da respiração microbiana e de composição da matéria orgânica. Dessa forma, as concentraçóes de OD na zona saturada deveriam ser, normalmente, baixas. Valores de OD acima de 1,0 $\mathrm{mg} \mathrm{O}_{2} / \mathrm{L}$, por exemplo, podem indicar que a redução microbiana de $\mathrm{O}_{2}$ é limitada, ou que o oxigênio é capaz de ser efetivamente transportado até a zona freática ou, ainda, a combinação desses dois fenômenos. Vale destacar também, que diversos compostos inorgânicos, principalmente os metálicos são sensivelmente afetados pela presença de OD (ROSE; LONG, 1988).

Referente aos sólidos totais (Figura 24), observam-se aumentos expressivos nos poços PJ1, PJ2 e PJ3 com

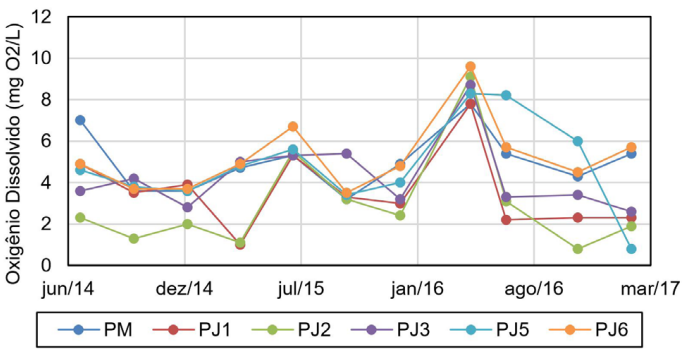

Figura 23. Concentraçóes de oxigênio dissolvido para as amostras de água dos poços.

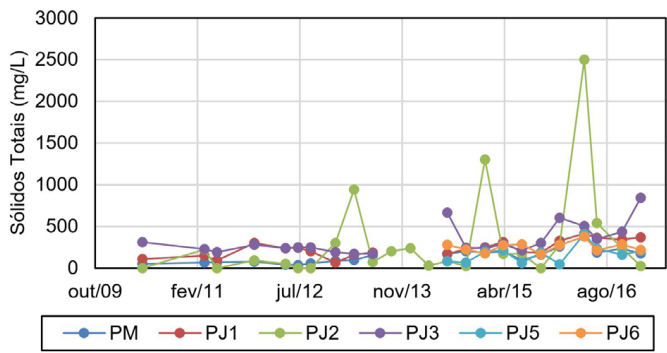

Figura 24. Concentraçôes de sólidos totais para as amostras de água dos poços.

picos acentuados, principalmente para o $\mathrm{PJ} 3$ em que atingiu o teor de $2500 \mathrm{mg} / \mathrm{L}$ em maio/2016. Estas são também evidenciadas pela elevada variabilidade observada no desvio padrão deste parâmetro (Tabela 3). Acredita-se que tal aumento pode estar relacionado ao tratamento do lixiviado uma vez que, verificou-se o aumento de sólidos sedimentáveis no efluente tratado em relaçáo ao bruto, conforme resultados da Tabela 2 e da Figura 8.

Por fim, cabe destacar a possibilidade de o solo no local do aterro estar exercendo efeito tampáo sobre os contaminantes oriundos do lixiviado visto que, segundo o estudo geológico realizado na área, caracteriza-se como sendo um solo argilo siltoso, o qual apresenta potencial de atenuação natural de contaminantes. Conforme Christensen et al. (2001), solos com alto teor de argila, como do aterro de estudo, apresentam elevada capacidade de troca catiônica que pode contribuir significativamente para a atenuação da pluma de lixiviado. 
Tabela 3. Resultados do Teste t para os parâmetros analisados dos poços de monitoramento.

\begin{tabular}{|c|c|c|c|c|c|c|c|c|c|c|}
\hline \multirow{2}{*}{ Parâmetro } & \multicolumn{2}{|c|}{ PJ1 } & \multicolumn{2}{|c|}{ PJ2 } & \multicolumn{2}{|c|}{ PJ3 } & \multicolumn{2}{|c|}{ PJ5 } & \multicolumn{2}{|c|}{ PJ6 } \\
\hline & $\mathbf{t}^{*}$ & tc & $\mathbf{t}^{*}$ & tc & $\mathbf{t}^{*}$ & tc & $\mathbf{t}^{*}$ & tc & $\mathbf{t}^{*}$ & tc \\
\hline $\mathrm{pH}$ & $-0,485$ & 1,847 & $-0,544$ & 1,833 & $-0,373$ & 1,833 & $-0,003$ & 1,833 & $-0,534$ & 1,833 \\
\hline Alcalinidade Total & $-1,683$ & 2,195 & $-2,376$ & 2,171 & 2,554 & 2,253 & $-0,301$ & 2,301 & $-1,843$ & 2,243 \\
\hline Alumínio & 2,732 & 4,221 & 1,710 & 4,299 & 2,494 & 4,295 & 1,311 & 4,302 & 1,101 & 4,289 \\
\hline Arsênio & 0,000 & 0,000 & 0,000 & 0,000 & 0,000 & 0,000 & 0,000 & 0,000 & 0,000 & 0,000 \\
\hline Bário & 0,609 & 4,125 & 0,005 & 3,756 & $-0,175$ & 3,270 & $-1,419$ & 3,661 & 0,144 & 3,570 \\
\hline Boro & 1,676 & 12,649 & $-3,530$ & 10,739 & 1,024 & 12,654 & 0,403 & 12,674 & 0,403 & 12,674 \\
\hline Cádmio & 0,274 & 2,431 & $-1,118$ & 2,132 & $-1,118$ & 2,132 & 0,553 & 2,665 & $-1,118$ & 2,132 \\
\hline Chumbo & 1,070 & 2,365 & 2,598 & 2,306 & 2,134 & 2,306 & 1,982 & 2,365 & 1,118 & 2,776 \\
\hline Cloretos & 0,772 & 2,155 & 1,141 & 2,168 & $-0,636$ & 2,059 & $-4,466$ & 2,079 & $-0,804$ & 2,101 \\
\hline Coliformes Term. & 1,000 & 2,768 & 0,991 & 2,444 & $-0,716$ & 2,055 & 1,090 & 2,776 & $-0,413$ & 2,118 \\
\hline Coliformes Tot. & 1,179 & 2,569 & 1,144 & 4,288 & 0,688 & 2,722 & 1,077 & 2,776 & 1,031 & 2,773 \\
\hline $\mathrm{CE}$ & 1,669 & 2,211 & 0,885 & 2,212 & 1,169 & 2,103 & $-2,856$ & 2,166 & $-0,451$ & 2,084 \\
\hline Cr VI & 0,000 & 0,000 & 0,000 & 0,000 & 0,000 & 0,000 & 0,000 & 0,000 & 0,000 & 0,000 \\
\hline Cromo Total & $-0,623$ & 2,055 & 0,826 & 2,504 & 1,196 & 2,317 & 0,554 & 2,246 & 0,164 & 2,192 \\
\hline & 1,746 & & & & 1,600 & 2,209 & & & 0,833 & 2,346 \\
\hline DQO & 0,026 & 2,017 & 0,565 & 2,010 & 0,809 & 2,115 & 0,661 & 2,120 & $-0,691$ & 1,936 \\
\hline Fosfato Total & $-0,304$ & 9,278 & 1,156 & 3,731 & $-0,584$ & 6,020 & $-0,608$ & 8,231 & $-1,127$ & 5,159 \\
\hline Manganês & 0,039 & 3,589 & $-0,934$ & 2,920 & $-0,993$ & 2,922 & 0,754 & 4,052 & $-0,354$ & 3,267 \\
\hline Mercúrio & 0,828 & 2,544 & $-1,095$ & 2,015 & $-1,095$ & 2,015 & $-1,095$ & 2,015 & $-1,095$ & 2,015 \\
\hline Níquel & 1,075 & 2,306 & 1,533 & 2,301 & 1,060 & 2,338 & 1,179 & 2,363 & 1,104 & 2,382 \\
\hline Nitrato & 1,453 & 4,300 & 1,893 & 4,300 & 1,125 & 4,292 & $-0,633$ & 3,467 & 0,486 & 3,428 \\
\hline Nitrito & 1,414 & 0,000 & 1,109 & 12,460 & 0,000 & 9,510 & 1,406 & 12,636 & 0,000 & 9,510 \\
\hline OD & 5,883 & 2,147 & 4,005 & 2,170 & 7,985 & 2,115 & 7,074 & 2,155 & 9,602 & 2,115 \\
\hline Óleos e Graxas totais & 4,232 & 0,000 & 0,362 & 11,233 & $-0,525$ & 8,491 & $-2,426$ & 0,000 & 1,070 & 12,524 \\
\hline SDT & 3,459 & 2,074 & 1,829 & 2,137 & 1,388 & 2,104 & $-1,781$ & 2,061 & 0,295 & 2,065 \\
\hline ST & 2,318 & 2,215 & 2,759 & 2,208 & 2,888 & 2,245 & $-1,372$ & 2,206 & 1,112 & 2,133 \\
\hline Sulfato & 0,788 & 2,307 & 0,356 & 2,196 & 1,539 & 2,305 & 0,594 & 2,265 & 1,116 & 2,345 \\
\hline Sulfeto & 1,581 & 2,377 & 1,414 & 3,267 & 0,000 & 0,000 & 1,414 & 1,766 & 0,000 & 0,000 \\
\hline Turbidez & 0,874 & 4,293 & 1,571 & 4,288 & 0,910 & 4,291 & 0,415 & 4,186 & 0,092 & 4,175 \\
\hline Zinco & 1,433 & 6,448 & $-1,109$ & 2,920 & $-1,054$ & 2,945 & 0,638 & 4,094 & $-0,487$ & 3,246 \\
\hline
\end{tabular}

\section{ANÁLISE ESTATÍSTICA}

Todos os dados analisados na água subterrânea foram comparados estatisticamente através do teste t, onde foi comparado se ocorreu ou náo aumento significativo entre pelo menos um dos poços a jusante (PJ1, PJ2, PJ3, PJ5, PJ6) em relação ao poço de referência a montante (PM4). Após a aplicação do Teste $\mathrm{t}$ pode se perceber que houve aumento significativo de alcalinidade total para o $\mathrm{PJ} 3, \mathrm{~Pb}$ para o $\mathrm{PJ} 2, \mathrm{DBO} 5$ para o PJ2, OD para todos os poços PJ1, PJ2, PJ3, PJ5, PJ6, SDT para o PJ1 e ST para o PJ1, PJ2, PJ3, conforme assinalados na Tabela 3. Para os demais parâmetros não houve variação significativa.

Dentre os parâmetros que obtiveram aumento significativo, a alcalinidade total e ST não possuem VMP na legislação, já em análises anteriores a presença de $\mathrm{Pb}$ ultrapassou o VMP das legislaçóes, como anteriormente observado (Figura 15). Já OD teve aumento significativo em todos os poços. Ainda, o PJ2 
teve aumento significativo de $\mathrm{DBO} 5$ o que representa um aumento da carga orgânica biodegradável. A presença do $\mathrm{Pb}$, e dos valores altos $\mathrm{DBO} 5$ podem influir sobre uma contaminação do lixiviado do aterro sanitário, já que ocorreram diferenças significativas em relação ao poço montante que fica em área anterior à disposição dos resíduos.

\section{CONCLUSÓES}

Neste estudo, a caracterização físico-química do lixiviado bruto e tratado, e o comparativo com VMP estabelecidos nas resoluçóes brasileiras vigentes, permitiram verificar que, dos 40 parâmetros avaliados, 9 ainda estavam presentes no efluente tratado em concentraçóes superiores ao limite máximo, sendo eles: cloreto, coliformes termotolerantes, DBO, DQO, ferro, manganês, nitrogênio amoniacal, SST e sólidos sedimentáveis. Quanto a eficiência do tratamento atual, verificou-se uma média de $60 \%$ de remoção dos parâmetros analisados.

Referente a análise do fluxo das águas subterrâneas, verificou-se que os poços de monitoramento estão alocados corretamente, de forma em que é possível avaliar a influência do aterro sanitário sobre o lençol freático. Já para a avaliação da qualidade da água subterrânea local, dos 30 parâmetros analisados, 10 parâmetros ultrapassaram o VMP da resolução, sendo estes: cádmio, chumbo, níquel, mercúrio, cromo total, alumínio, manganês, turbidez, coliformes totais e termotolerantes. Quando estes resultados foram comparados estatisticamente, verificou-se que alcalinidade total, $\mathrm{Pb}, \mathrm{OD}, \mathrm{DBO} 5 \mathrm{SDT}$ e ST apresentaram um aumento significativo em pelo menos uma das análises dos poços à jusante, em relaçáo ao poço à montante, mas somente o $\mathrm{Pb}$ e $\mathrm{DBO} 5$ apresentaram concentração acima do VMP estabelecidos na resolução, inferindo que a atividade de disposição dos resíduos está interferindo na qualidade da água subterrânea. Além disso, verifica-se a possibilidade de o solo apresentar capacidade de atenuação de certos compostos, resultando na observação de concentraçóes mais baixas nos resultados das amostras da água subterrânea.

Contudo, espera-se que este estudo forneça subsídios para compreensão dos impactos da disposição de resíduos sobre a qualidade dos recursos naturais nas proximidades do aterro sanitário de Palmeiras das Missóes, bem como para adoção de medidas para melhoria do tratamento do lixiviado, buscando atender ao VMP de todos os parâmetros físico-químicos estabelecidos pelas normativas vigentes. Também, espera-se que os resultados apresentados possam auxiliar na gestão dos recursos hídricos subterrâneos na área. Por fim, este estudo demonstra que, mesmo aterros sanitários devidamente licenciados estão suscetíveis à ocorrência de deficiências nos seus sistemas constituintes, que ao longo do tempo, podem acarretar em sérios problemas ambientais.

\section{REFERENCIAS}

ADAMCOVÁ, D. et al. Environmental assessment of the effects of a municipal landfill on the content and distribution of heavy metals in Tanacetum vulgare L. Chemosphere, v. 185, p. 1011-1018, 2017.

AHARONI, I.; SIEBNER, H.; DAHAN, O. Application of vadose-zone monitoring system for real-time characterization of leachate percolation in and under a municipal landfill. Waste Management, 2017.

AL SABAHI, E. et al. The characteristics of leachate and groundwater pollution at municipal solid waste landfill of lbb City, Yemen. American Journal of Environmental Sciences, v. 5, n. 3, p. 256-266, 2009.

AMERICAN PUBLIC HEALTHASSOCIATION - APHA. Standard methods for the examination of water and wastewater. Washington: APHA, 2005. AMERICAN PUBLIC HEALTHASSOCIATION -APHA. Standart methods for the examination of water and wastewater. Washington: APHA, 2012. 
ASSOCIAÇÃO BRASILEIRA DE NORMAS TÉCNICAS - ABNT. NBR 10157: Aterros de resíduos perigosos - critérios para projeto, construção e operação. ABNT, 1987.

ASSOCIAÇÃO BRASILEIRA DE NORMAS TÉCNICAS - ABNT. NBR 10.004/2004: Resíduos sólidos - classificação. ABNT, 2004.

BACCINI, P. et al. Water and element balances of municipal solid waste landfills. Waste Management \& Research, v. 5, n. 1, p. 483-499, 1987.

BECK, M. H. et al. Monitoramento das águas subterrâneas e lixiviado do local de disposição dos resíduos sólidos urbanos do município de Passo Fundo - RS. Rega, v. 7, n. 1, p. 29-44, 2010.

BRASIL. Lei no 12.305/2010. Plano nacional de resíduos sólidos. Diário Oficial [da] República Federativa do Brasil, Brasilia, p. 103, 2011 a.

BRASIL. MINISTÉRIO DA SAÚDE. Portaria No 2.914/2011: Dispõe sobre os procedimentos de controle e de vigilância da qualidade da água para consumo humano e seu padrão de potabilidade. Diário Oficial [da] República Federativa do Brasil, 2011b.

BRASIL. MINISTÉRIO DAS CIDADES. Diagnóstico do manejo de resíduos sólidos urbanos - 2016. Brasilia: Secretaria Nacional de Saneamento Ambiental, 2018.

CALVO, F. et al. Environmental diagnosis methodology for municipal waste landfills. Waste Management, New York, v. 25, n. 8, p. 768-779, 2005.

CASTILHOS JUNIOR, A. B. et al. Tratamento de lixiviados de aterro em sistema de lagoas. In: CASTILHOS JUNIOR, A. B. et al. Estudos de caracterização e tratabilidade de lixiviados de aterros sanitários para as condições brasileiras. Rio de Janeiro: ABES, 2009. p. 140-171.

CHRISTENSEN, T. H. et al. Biogeochemistry of land leachate plumes. Applied Geochemistry, v. 16, p. 659-718, 2001.

CONSELHO NACIONALDO MEIO AMBIENTE - CONAMA. Resolução CONAMAN 396/2008: Dispõe sobre a classificação e diretrizes ambientais para o enquadramento das águas subterrâneas e dá outras providências. Diário Oficial [da] República Federativa do Brasil, 2008, p. 64-68.

CONSELHO NACIONAL DO MEIO AMBIENTE - CONAMA. Resolução No 430/2011. Dispõe sobre as condições e padrões de lançamento de efluentes, complementa e altera a Resolução no 357, de 17 de março de 2005, do Conselho Nacional do Meio Ambiente-CONAMA. Diário Oficial [da] República Federativa do Brasil, 2011, p. 89.

CONSELHO ESTADUAL DO MEIO AMBIENTE - CONSEMA. Resolução CONSEMA No 355/2017. Dispõe sobre os critérios e padrões de emissão de efluentes líquidos para as fontes geradoras que lancem seus efluentes em águas superficiais no Estado do Rio Grande do Sul. CONSEMA, 2017. p. 7.

CONTRERA, R. C. et al. First-order kinetics of landfill leachate treatment in a pilot-scale anaerobic sequence batch biofilm reactor. Journal of Environmental Management, v. 145, p. 385-393, 2014.

CONTRERA, R. C.; ZAIAT, M.; SCHALCH, V. Tratamento biológico de lixiviados de aterros sanitários utilizando Reator Anaeróbio Horizontal de Leito Fixo (RAHLF). Minerva, v. 2, n. 1, p. 65-74, 2006.

EL-SALAM, M. M. A.; ABU-ZUID, G. I. Impact of landfill leachate on the groundwater quality: a case study in Egypt. Journal of Advanced Research, v. 6, n. 4, p. 579-586, 2015.

HAN, Z. et al. A review of groundwater contamination near municipal solid waste landfill sites in China. The Science of the Total Environment, v. 569-570, p. 1255-1264, 2016.

HOSSAIN, M. L.; DAS, S. R.; HOSSAIN, M. K. Impact of landfill leachate on surface and ground water quality. Journal of Environmental Science and Technology, v. 7, n. 6, p. 337-346, 2014.

HU, L.; DU, Y.; LONG, Y. Relationship between H2S emissions and the migration of sulfur-containing compounds in landfill sites. Ecological Engineering, v. 106, p. 17-23, 2017.

JOVANOV, D.; VUJIĆ, B.; VUJIĆ, G. Optimization of the monitoring of landfill gas and leachate in closed methanogenic landfills. Journal of Environmental Management, v. 216, p. 32-40, 2018. 
KJELDSEN, P. et al. Critical reviews in environmental science and technology present and long-term composition of MSW landfill leachate. Critical Reviews in Environmental Science and Technology, v. 32, n. 324, p. 37-41, 2002.

KULIKOWSKA, D.; KLIMIUK, E. The effect of landfill age on municipal leachate composition. Bioresource Technology, v. 99, n. 13, p. 5981$5985,2008$.

LEE, G. F.; JONES-LEE, A. Dry tomb land'fills. MSW Management, v. 6, n. 1, p. 82-89, 1996.

LIMA, R. M. et al. Spatially distributed potential of landfill biogas production and electric power generation in Brazil. Waste Management, New York, v. 74, p. 323-334, 2018.

MAITI, S. K. et al. Characterization of leachate and its impact on surface and groundwater quality of a closed dumpsite - a case study at Dhapa, Kolkata, India. Procedia Environmental Sciences, v. 35, p. 391-399, 2016.

MANZO, C. et al. Top-down approach from satellite to terrestrial rover application for environmental monitoring of landfills. The Science of the Total Environment, v. 584-585, p. 1333-1348, 2017.

$\mathrm{MAO}, \mathrm{X}$. et al. Remediation of ammonia-contaminated groundwater in landfill sites with electrochemical reactive barriers: A bench scale study. Waste Management, New York, v. 78, p. 69-78, 2018.

MELO, E. F. R. Q. et al. Mecanismo de atenuação natural de metais em solos de antigas áreas de disposição de resíduos sólidos urbanos. In: VI SIMPÓSIO INTERNACIONAL DE QUALIDADE AMBIENTAL, 6., 2008, Porto Alegre. Anais... Porto Alegre, 2008

MOR, S. et al. Leachate characterization and assessment of groundwater pollution near municipal solid waste landfill site. Environmental Monitoring and Assessment, v. 118, n. 1-3, p. 435-456, 2006.

MOTURI, M. C. Z.; RAWAT, M.; SUBRAMANIAN, V. Distribution and fractionation of heavy metals in solid waste from selected sites in the industrial belt of Delhi, India. Environmental Monitoring and Assessment, v. 95, n. 1-3, p. 183-199, 2004.

NAVEEN, B. P. et al. Physico-chemical and biological characterization of urban municipal landfill leachate. Environmental Pollution, v. 220, p. $1-12,2017$.

PANAHIFARD, M. et al. Heavy metals monitoring in leachate from landfill site of Qazvin, Iran. Archives of Hygiene Sciences, v. 6, n. 1, p. $44-48,2017$.

PIVATO, A.; DI SANTE, M.; MORETTO, C. G. Risk assessment: a hindrance or a help to landfill management? Waste Management (New York, N.Y.), v. 63, p. 1-2, 2017.

REGADÍO, M. et al. Pollution profiles and physicochemical parameters in old uncontrolled landfills. Waste Management (New York, N.Y.), v. 32, n. 3, p. 482-497, 2012.

ROSE, S.; LONG, A. Monitoring dissolved oxygen in ground water: some basic considerations. Ground Water Monitoring and Remediation, p. 93-97, 1988.

SCOTT, J. et al. Landfill management, leachate generation, and leach testing of solid wastes in Australia and overseas. Critical Reviews in Environmental Science and Technology, v. 35, n. 3, p. 239-332, 2005.

TANG, Q. et al. Impact of biological clogging on the barrier performance of landfill liners. Journal of Environmental Management, v. 222, n. May, p. 44-53, 2018.

TCHBANOGLOUS, G.; THESSEN, H.; VIGIL, S. A. Composicion y caracteristicas, generacion, movimento y control de los gases de vertedoro. Mc Graw Hill, 1994.

UNIVERSIDADE ESTADUAL PAULISTA - UNESP. Projeto piloto de conservação dos recursos de solo e água e irrigação coletiva nas microbacias hidrográficas dos córregos Sucuri, Bacuri e Macumã em Palmeira d'Oeste - SP. 2000. Disponível em: <http://www.feis.unesp.br/irrigacao/ noroeste/noroeste.htm>. Acesso em: 9 jul. 2018. 
WANG, S. et al. Removal of organic matter and ammonia nitrogen from landfill leachate by ultrasound. Ultrasonics Sonochemistry, v. 15, n. 6 , p. 933-937, 2008.

YOUCAI, Z;; ZIYANG, L. Pollution control and resource recovery: municipal solid wastes at landfill. In: Pollution control and resource recovery. municipal solid wastes at landfill. Cambridge: Elsevier, 2016. p. 388.

ZHAN, T. L. T. et al. Vertical migration of leachate pollutants in clayey soils beneath an uncontrolled landfill at Huainan, China: a field and theoretical investigation. The Science of the Total Environment, v. 470-471, p. 290-298, 2014.

ZILZ, L.; SILVA, J. D.; PINHEIRO, A. Eficiência do melaço como fonte de carbono na remoção de nitrito em lixiviados de aterros sanitários. Engenharia Sanitaria e Ambiental, v. 19, n. 1, p. 97-104, 2014.

ZOPPAS, F. M.; BERNARDES, A. M.; MENEGUZZI, Á. Parâmetros operacionais na remoção biológica de nitrogênio de águas por nitrificação e desnitrificação simultânea. Engenharia Sanitaria e Ambiental, v. 21, n. 1, p. 29-42, 2016.

Lucimara Bragagnolo

Fronteira Sul - Campus Erechim. Erechim, RS, Brasil. email: lucimarabragagnolo@hotmail.com

Contribuição do autor

Tabulação de informaçôes, elaboração de mapas e gráficos, levantamento bibliográfico e redação.
Suéllen Tonatto Ferrazzo
Fronteira Sul - Campus Erechim. Erechim, RS, Brasil. email: suellenferrzzo@hotmail.com

Contribuição do autor

Levantamento bibliográfico e redação.

Fernanda Machado Brum
Universidade Federal da
Fronteira Sul - Campus Erechim. Erechim, RS, Brasil.
email: fe896@hotmail.com

Contribuição do autor

Levantamento de dados, aplicação da análise estatística.

Eduardo Pavan Korf

Fronteira Sul - Campus Erechim. Erechim, RS, Brasil.
email: eduardo.korf@uffs.edu.br

Contribuição do autor

Coordenação da pesquisa, auxílio na discussão dos resultados das análises e revisão do manuscrito.

Altemir José Mossi

Universidade Federal da Fronteira Sul - Campus Erechim. Erechim, RS, Brasil. email: altemir.mossi@uffs.edu.br

Contribuição do autor

Coordenação da pesquisa e auxílio na discussão dos resultados das análises. 


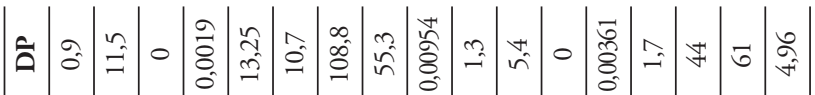

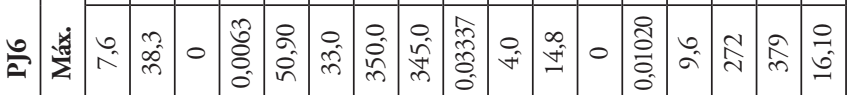

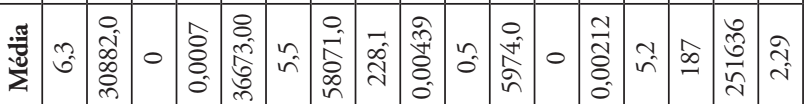

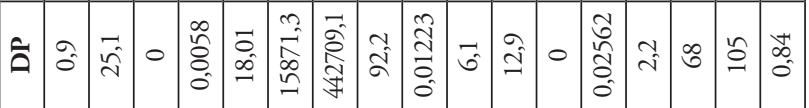

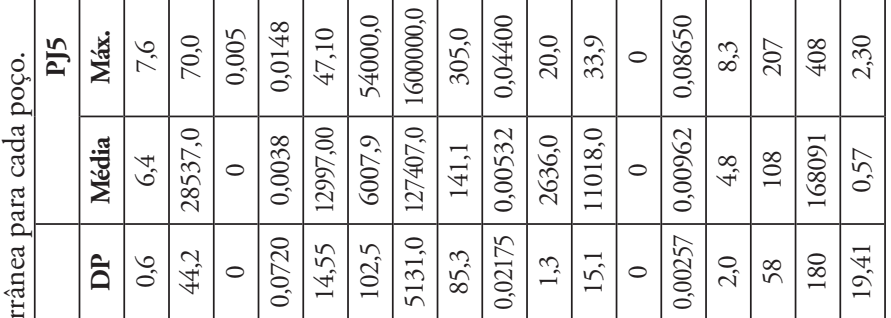

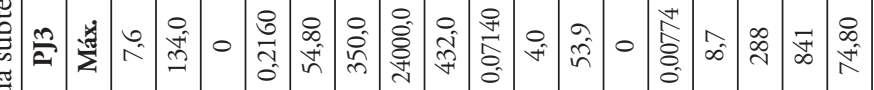

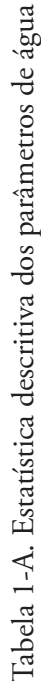

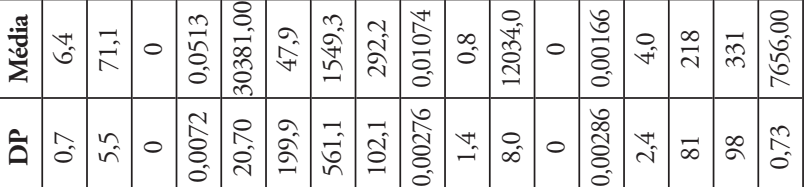

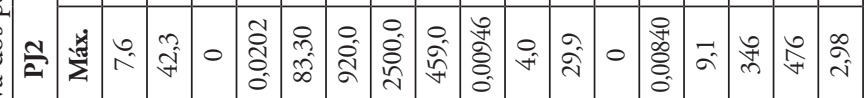

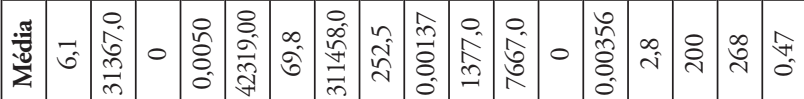

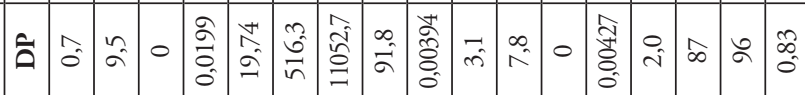

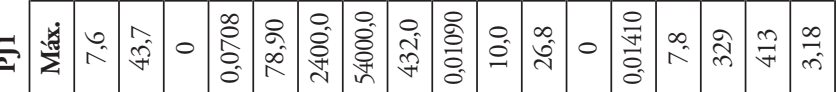

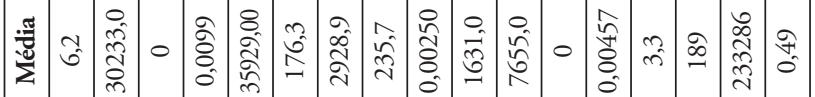

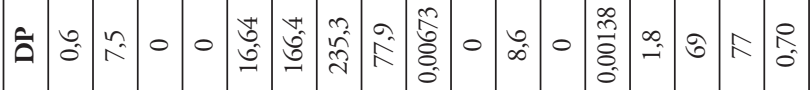

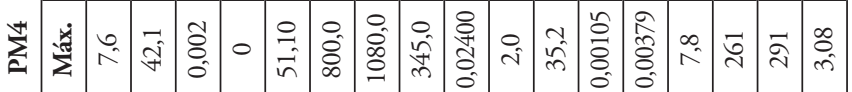

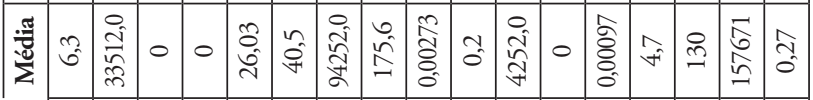

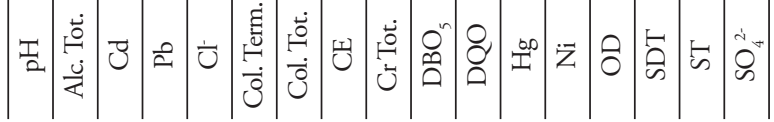

